\title{
CO-MOVEMENT OF AUSTRALIAN STATE BUSINESS CYCLES
}

\author{
David Norman and Thomas Walker
}

Preliminary version. Please do not quote without authors' permission. This version June 2004.

Economic Group

Reserve Bank of Australia

We are grateful to Andrew Stone, Jacqui Dwyer, Jonathan Kearns, Marion Kohler, Tony Richards and Michael Kouparitsas for their help and advice, and to Lyn Grivell for research assistance. We also thank our colleagues at the Reserve Bank of Australia for helpful comments. Any errors are ours alone. The views expressed herein are those of the authors and do not necessarily reflect the views of the Reserve Bank of Australia. 


\begin{abstract}
We use a variety of techniques to examine the nature and degree of co-movement among Australian state business cycles. Our results indicate that these cycles move closely together, with particularly strong links between the cycles of the larger states. This finding is robust to a range of statistical measures. We also use an unobserved components model in an attempt to distinguish the sources of this comovement. While our results must be interpreted with caution given the limited amount of data available, they suggest that the major source of cyclical fluctuation in state activity is shocks that are common to all states. Region-specific shocks appear to have a moderate influence on cyclical fluctuations, while spillovers of such shocks from one state to another seem to play only a minor role. These findings are consistent with the results of recent studies for the United States, Canada and Europe, where common shocks have also been found to dominate regional cyclical activity.
\end{abstract}

JEL Classification Numbers: C22, E32, R11

Keywords: business cycles, concordance, unobserved components, Australia 


\section{Table of Contents}

1. Introduction 2

2. Previous Research and Data Issues 4

3. Statistical Approaches 5

3.1 The extent of co-movement 5

3.2 Why state cycles might co-move: preliminary observations 12

4. An Unobserved Components Model 15

4.1 Background 15

$\begin{array}{lll}4.2 & \text { Specification } & 16\end{array}$

5. Modelling Results $\quad 18$

5.1 State Final Demand and Hours Worked 19

5.2 Gross State Product and Hours Worked 26

$\begin{array}{ll}\text { 6. Conclusion } & 28\end{array}$

Appendix A: Industrial Structure and Cyclical Co-Movement 29

Appendix B: Modelling Business Cycles $\quad 30$

Appendix C: Details on the Unobserved Components Model 32

Appendix D: Further Unobserved Components Model Results 35

$\begin{array}{lll}\text { Appendix E: Data Sources } & 41\end{array}$

$\begin{array}{ll}\text { References } & 42\end{array}$ 


\section{Introduction}

Do Australian state business cycles move synchronously? While there is a wealth of literature addressing the issue of cyclical co-movement among countries, very little focus has been given to the issue at a state level, despite its importance for policy-makers. The extent of co-movement of state activity has implications for our understanding of the economy as a whole, and for the role of national policy instruments in smoothing business cycles. Furthermore, an understanding of the sources of cyclical co-movement could also help policy-makers better assess the major risks to the economy, and improve their response to economic shocks, given that purely regional shocks may involve a different adjustment of capital and labour than shocks affecting all states.

An examination of the growth of economic activity across Australian states, using state final demand as the measure of activity, suggests that economic cycles are quite closely synchronised (Figure 1). ${ }^{1}$ This is particularly true of the three largest states, where the characteristics of their cycles (timing, duration and amplitude) appear to have been very similar since the mid 1980s. The cycles of the three smaller states appear more disparate, but even these states share some cyclical similarities.

For reasons discussed shortly, we focus on SFD as a measure of activity in this paper, rather than the broader measure of output, gross state product. We limit our analysis to the six states of Australia which, in order of economic size, are New South Wales (NSW), Victoria (Vic), Queensland (QLD), Western Australia (WA), South Australia (SA) and Tasmania (Tas). Our analysis does not include the two Territories, so henceforth the words 'aggregate' and 'national' refer to the sum of the six Australian states. Gross state product for the six states comprised 97 per cent of total GDP in 2002/03. 
Figure 1: Cycles in State Economic Activity

Year-Ended Growth in State Final Demand

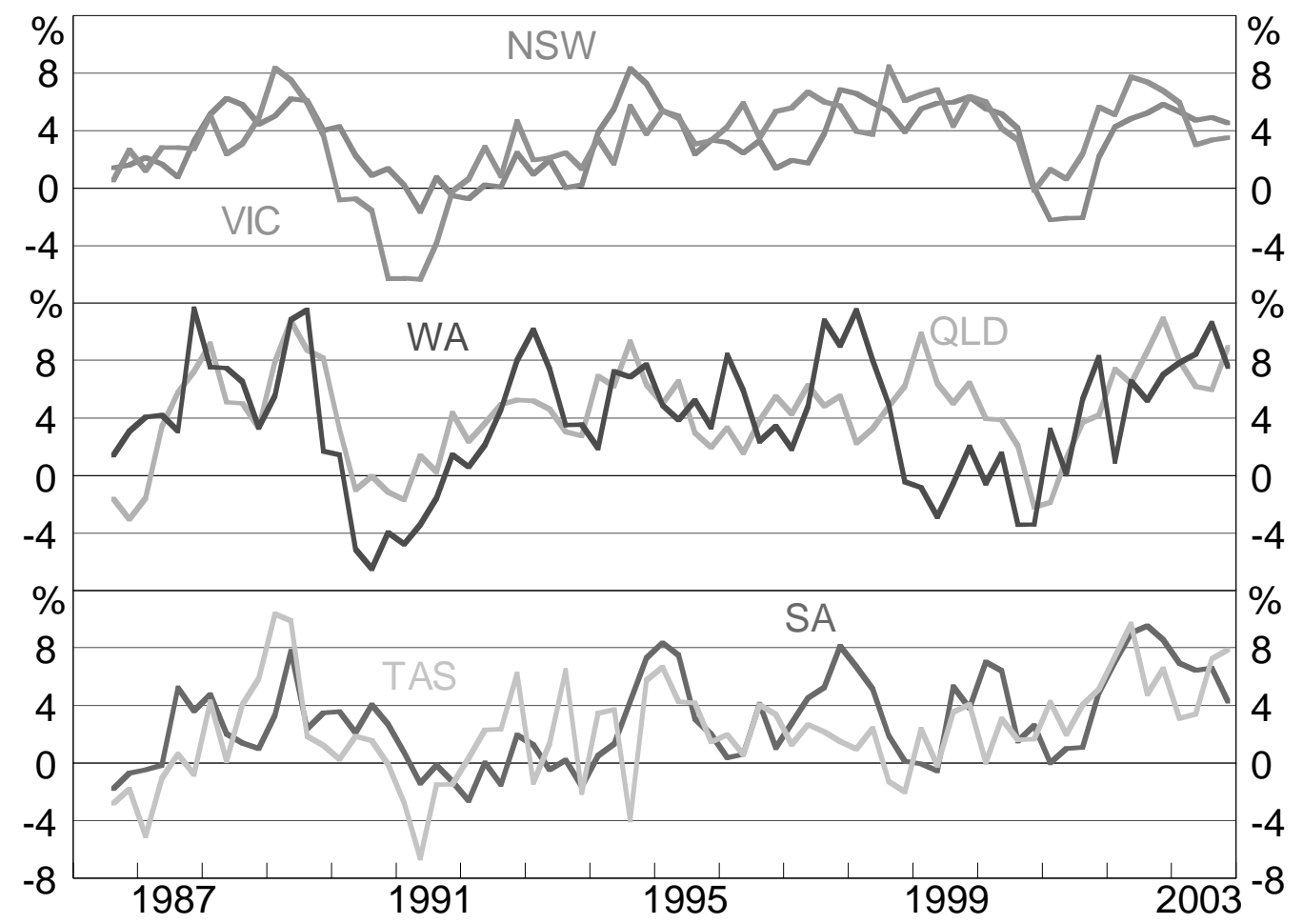

The aim of this paper is to examine the extent and sources of business cycle comovement among Australian states. While there are a number of studies focussing on regional co-movement in other countries, there has been little research on this issue for Australia. A notable exception is Dixon and Shepherd's (2001) study of unemployment in Australian states, which found correlations of between 0.5 and 0.7 for state unemployment rates, along with evidence that cyclical activity in the five largest states is driven by a common cycle. ${ }^{2}$ Section 3 of our paper expands this research by focusing on more direct measures of the business cycle, and by looking at a range of alternative measures of co-movement. Consistent with Dixon and Shepherd, we also find that state cyclical activity is quite closely linked. Sections 4 and 5 then look at what may account for this co-movement, a question which, to the best of our knowledge, has not yet been addressed in Australia. In support the findings in Section 3, the results indicate that Australian state activity is dominated by a common cycle, with region-specific fluctuations and spillovers of fluctuations between states making less substantial contributions.

2 There are other studies that look at synchronisation of state labour markets over a longer time frame than a cycle (for example, Debelle and Vickery 1999). 


\section{Previous Research and Data Issues}

While there are few comprehensive studies of co-movement of cyclical activity between Australian states, there are a number of studies suggesting quite close linkages exist between US regions. Kouparitsas (2002) and Carlino and Sill (1997), for example, find that correlations of per capita personal income cycles among regions of the USA range from 0.6 to 0.8, and Owyang, Piger and Wall (2003) find that turning points in the economic cycles of US states occur at broadly the same time as turning points nationally. Similar results have also been found for regions within European countries (Barrios and de Lucio 2003, Barrios et al 2003). ${ }^{3}$

In addition to the question of whether strong cyclical linkages exist between different regions, researchers have also begun to ask what might account for observed co-movement. Throughout this paper, we look at two alternative types of shock to economic activity: common shocks, which affect all states simultaneously, and idiosyncratic shocks, which are specific to individual states. ${ }^{4}$ We also include a mechanism for idiosyncratic shocks to spill over from the state in which they originate to other states. If state cycles are driven to a large extent by idiosyncratic shocks, they will tend to display individual dynamics (i.e. they will not co-move), unless those shocks then spill over to other states. In contrast, if state cycles are heavily influenced by common shocks, they will tend to display similar dynamics. Consequently, common shocks and spillovers create co-movement, whilst idiosyncratic shocks reduce co-movement. The available research on regional economies suggests that common shocks are a major source of cyclical comovement between states, although spillovers are also non-trivial

3 These studies are also consistent with cross-country correlation results, which show that cyclical activity is correlated among certain country blocs, such as North America and the UK (Stock and Watson 2003), European nations (Artis, Kontelemis and Osborn 1997) and between Australia, the USA and New Zealand (Hall, Kim and Buckle 1998).

4 Examples of shocks which we might expect to be classified as common are changes in monetary policy, the exchange rate, or world economic activity - things which affect all states. In principle, however, if such changes affect activity in different states with different lags, part of them might be classified as idiosyncratic rather than common shocks in this framework. Idiosyncratic shocks are typically assumed to include changes to state fiscal policy, regional droughts or local bank failures. These sometimes spill over (are transmitted) to other states through channels such as trade or FDI linkages. Shocks to a particular industry could be either common or idiosyncratic, depending on the similarity of states' industrial structures. 
(Kouparitsas 2002). Cross-country research has yielded similar results, although consistent with the smaller number of common shocks, spillovers play a greater role in cross-country dynamics (Norrbin and Schlagenhauf 1996; Clark and Shin 2000).

The difficulty with examining such issues at a sub-national level is the scarcity of comprehensive measures of economic activity. The most comprehensive measure of state economic activity, gross state product (GSP), is only consistently available for Australian states on an annual basis (from 1989/90), which limits its usefulness in assessing business cycle synchronicity. Consequently, we have chosen to use two alternative proxies of economic activity in our analysis: state final demand (SFD) and hours worked. Both measures have limitations. SFD, which measures total domestic spending in each state and is akin to domestic final demand at a national level, excludes important components of economic activity, particularly external trade (both international and interstate). This deficiency has implications for our assessment of the importance of spillovers, given that trade is often seen as a primary avenue for the transmission of shocks from one state to another. In contrast, hours worked data should capture changing conditions in a state's external sector, but information from the labour market is only an indirect estimate of economic activity, and shocks may be observed with a lag. In what follows, we use both measures to try to mitigate these deficiencies, while in Section 5.2 we consider the effects on our results of using a constructed measure of GSP.

\section{Statistical Approaches}

\subsection{The extent of co-movement}

In constructing a measure of 'the cycle', one must choose a method of removing high-frequency noise from the data. Our primary method follows the growth cycles literature, whereby trends and volatility are removed from the data using Baxter and King's (1999) band-pass filter. ${ }^{5}$ This filter was chosen in preference to others

A band-pass filter is the difference between a low-pass filter (which removes all fluctuations with periodicity less than or equal to $\underline{\omega}$ ) and a high-pass filter (which removes all fluctuations with a periodicity greater than or equal to $\bar{\omega}$ ). Corresponding to Burns and Mitchell's (1946) 
such as the Hodrick-Prescott filter or first-differencing, because it more effectively removes high-frequency information, and has been shown to introduce less distortion than the Hodrick-Prescott filter when a series is autoregressive (Pedersen 2001). Figure 2 shows the resulting cycles. It is clear from this that there is a high degree of synchronicity, particularly among the larger states. ${ }^{6}$

Figure 2: Band-Pass Filtered State Cycles

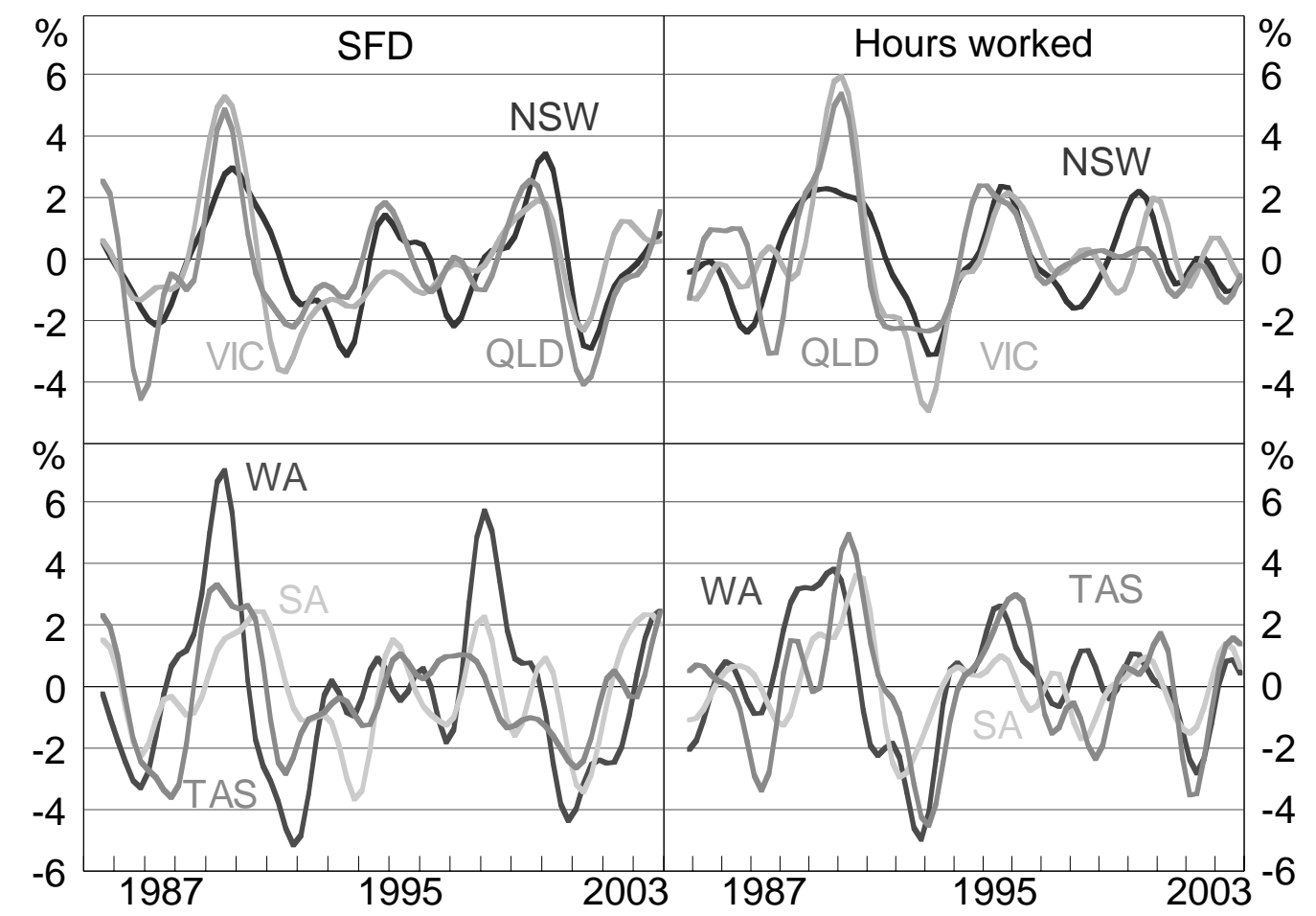

This can also be seen by examining the cross-state correlation of these band-pass filtered variables, shown in Table 1. For our sample size, the correlation between two independent random walks will only exceed 0.29 in absolute value in one per cent of random draws. ${ }^{7}$ All of the above correlations exceed this figure, so we

definition of a business cycle as one lasting between 6 and 32 quarters, we choose $\underline{\omega}=6$ and $\bar{\omega}=32$. A detailed analysis of the band-pass filter is given in Baxter and King (1999).

6 A 6,32 band-pass filter removes the first and last 12 observations. Given our short sample (1985:Q3 to 2003:Q4 for SFD and 1984:Q4 to 2003:Q4 for hours worked), we consider this an unacceptable data loss. To correct this, we used trends to extrapolate each series beyond their start and finish point, and allowed the band-pass filter to remove these observations. Consequently, the end-points of our series are less reliable than their mid-points and should be interpreted with caution.

7 Our calculations are based on the approximate $z$-statistic for hypothesis tests of correlations, as described in Miller and Miller (1999, page 477). For a test against the null of zero 
can be reasonably confident that SFD and hours worked for all states are contemporaneously correlated at high levels of significance. The statistical results also support our visual observations. The degree of synchronicity is greatest amongst the larger states, with average correlations between NSW, Victoria and Queensland of 0.73 using SFD and 0.70 using hours worked. Whilst correlations are lower among the smaller states ( 0.49 using SFD and 0.58 using hours worked), they also point to broadly synchronised cycles. Correlations across these two groups average 0.56 using SFD and 0.65 using hours worked.

\begin{tabular}{|c|c|c|c|c|c|c|}
\hline \multicolumn{7}{|c|}{ Table 1: Correlation Of Band-Pass Filtered Variables } \\
\hline & \multicolumn{6}{|c|}{ State Final Demand } \\
\hline & NSW & Victoria & Queensland & WA & SA & Tasmania \\
\hline NSW & 1.00 & & & & & \\
\hline Victoria & 0.68 & 1.00 & & & & \\
\hline Queensland & 0.74 & 0.77 & 1.00 & & & \\
\hline WA & 0.43 & 0.70 & 0.67 & 1.00 & & \\
\hline SA & 0.64 & 0.46 & 0.50 & 0.43 & 1.00 & \\
\hline Tasmania & 0.44 & 0.64 & 0.63 & 0.56 & 0.57 & 1.00 \\
\hline Australia & 0.88 & 0.90 & 0.90 & 0.75 & 0.66 & 0.66 \\
\hline \multirow[t]{3}{*}{ Average } & 0.58 & 0.65 & 0.66 & 0.56 & 0.52 & 0.57 \\
\hline & \multicolumn{6}{|c|}{ Hours worked } \\
\hline & NSW & Victoria & Queensland & WA & SA & Tasmania \\
\hline NSW & 1.00 & & & & & \\
\hline Victoria & 0.68 & 1.00 & & & & \\
\hline Queensland & 0.65 & 0.77 & 1.00 & & & \\
\hline WA & 0.59 & 0.71 & 0.70 & 1.00 & & \\
\hline SA & 0.53 & 0.65 & 0.61 & 0.53 & 1.00 & \\
\hline Tasmania & 0.73 & 0.68 & 0.64 & 0.58 & 0.62 & 1.00 \\
\hline Australia & 0.87 & 0.92 & 0.88 & 0.79 & 0.71 & 0.79 \\
\hline Average & 0.64 & $\mathbf{0 . 7 0}$ & 0.67 & 0.62 & 0.59 & 0.65 \\
\hline Notes: & $\begin{array}{r}\text { orrelatio } \\
\text { ustralia } \\
\end{array}$ & $\begin{array}{l}\text { lculated o } \\
\text { band-pass }\end{array}$ & $\begin{array}{l}\text { state-state corr } \\
\text { ered sum of all }\end{array}$ & $\begin{array}{l}\text { as, and } \\
\text { ates' SF } \\
\end{array}$ & $\begin{array}{l}\text { orrelat } \\
\text { rs wor } \\
\end{array}$ & th Australia. \\
\hline
\end{tabular}

correlation, the statistic $z=(\sqrt{n-3} / 2) \ln [(1+r) /(1-r)]$ is approximately standard normal, where $r$ is the estimated correlation coefficient and $n=71,74$ is the sample size for SFD and hours worked respectively. 
To assess whether the degree of synchronicity has changed substantially over our sample, we computed rolling correlations using a 30-quarter window. The results suggest that there has been no significant change in the degree of co-movement among the larger states, with the exception of the period around 1997-98 (Figure 3 , top panel). The declining correlation of state cycles in that period reflects the staggered entry into and recovery from the early 1990s recession across states, and the impact that this has on the rolling correlations as the recession period rolls out of our $71 / 2$ year window. The degree of synchronicity among the smaller states has been less stable (Figure 3, bottom panel), with the Western Australian and South Australian cycles increasingly correlated, but the Western Australian and Tasmanian economies increasingly divergent.

Figure 3: Rolling Correlations

Band-Pass Filtered State Final Demand

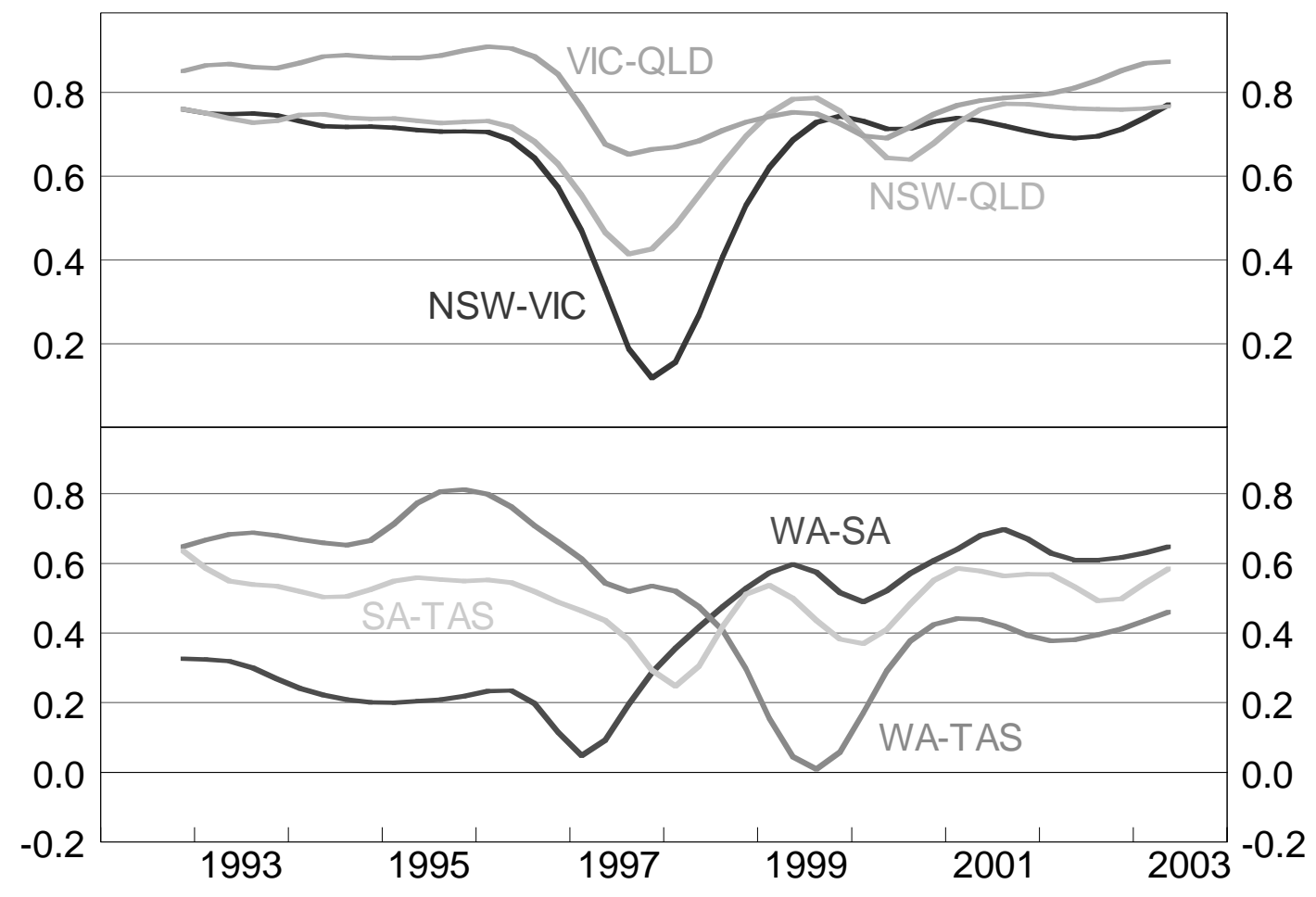

Note: Rolling correlations use 30-period windows, plotted relative to the sample end date.

An alternative way to assess co-movement is to consider classical business cycles, which are dated without removing trend growth. Although the literature since Burns and Mitchell's (1946) seminal paper has concentrated more on (detrended) growth cycles, some authors (for example, Harding and Pagan (2002)) criticise this approach because it requires imposing a particular structure on the (unknown) 
trend. As shown by Canova (1998), changes in the trend specification can indeed produce significant differences in the characteristics of the resulting cycles.

A well-known method for dating classical cycles is that set out in Wecker (1979), that two quarterly declines in activity represents a recession, while two successive quarters of growth represents an expansion. On this basis, peaks in activity are defined as periods where $\left\{\Delta \mathrm{y}_{\mathrm{t}}>0, \Delta \mathrm{y}_{\mathrm{t}+1}<0, \Delta \mathrm{y}_{\mathrm{t}+2}<0\right\}$, while troughs are dated by reversing the inequalities. However, classical cycles are also usually assumed to last at least six quarters, and the dating of a classical cycle therefore requires some censoring of the above algorithm (Harding and Pagan 2002). To do this, we also use the Bry and Boschan (1971) algorithm, now associated with the NBER, which dates peaks as periods where $\left\{\mathrm{y}_{\mathrm{t}}>\mathrm{y}_{\mathrm{t} \pm \mathrm{k}}\right\}$, where $\mathrm{k}=1,2$ for quarterly data, and vice versa for troughs. ${ }^{8}$

Figure 4 presents a graph of SFD in each state, with periods of classical recession shaded in grey. Focusing on the shaded periods, it is clear that a recession in one state is usually also experienced by other states. The most obvious period of concurrent recessions occurs between 1989 and 1991, when all states experienced classical recessions of varying lengths and severity. Only Western Australia and NSW did not share in the 1985-86 SFD recession, and all of the four largest states experienced a short-lived SFD recession in 2000-01. There is only one example of a state experiencing a recession alone (Queensland in 1995). However, it is also clear that the dates of these recessions are not perfectly synchronised. Most interestingly for our purposes, there are differences in the date at which each state enters recession.

8 These two algorithms generally produce very similar results. However, a series may record two quarterly declines and then not experience consecutive quarterly growth for some time, but still be increasing over the period because the magnitude of expansionary quarters outweighs the magnitude of contractionary quarters. In such situations, the Bry-Boschan algorithm suggests recording the period as an expansion, whereas Wecker's algorithm would record the period as a protracted recession. 
Figure 4: Classical Cycles

State Final Demand

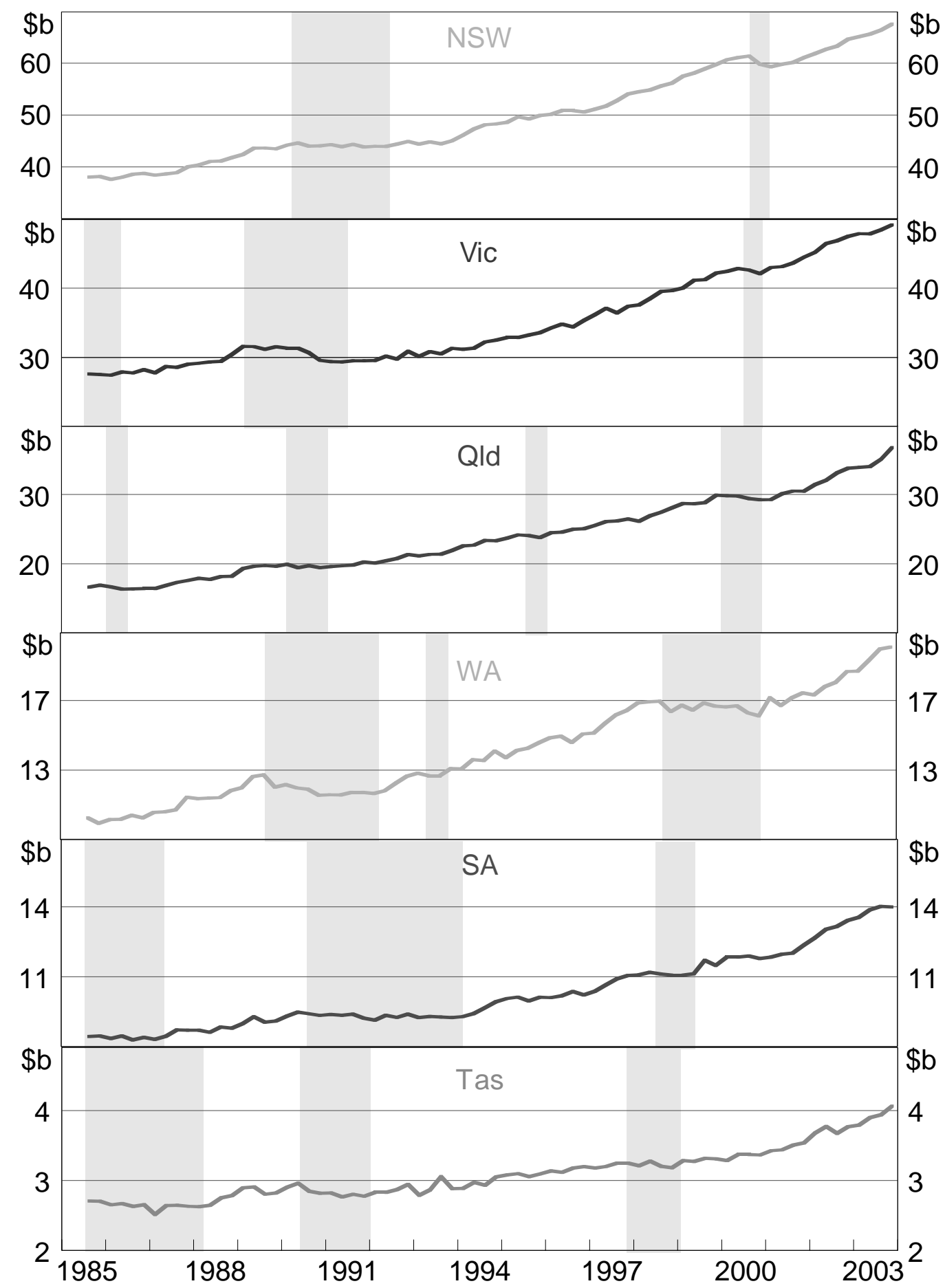

Note: Periods of grey shading represent classical recessions. 
For example, the major recession during this period (1989-91) began in Victoria, with Western Australia entering recession two quarters later, NSW and Queensland two quarters after that, and SA and Tasmania entering recession last. The time at which each state leaves each recession also differs, and it appears that recessions in South Australia and Tasmania have typically lasted somewhat longer than those in other states over the past two decades. Overall, this suggests that state business cycles are quite strongly synchronised, though far from uniform.

The degree of similarity between states' classical business cycles can also be assessed using the statistical framework provided by Harding and Pagan (2002). They suggest examining the degree of concordance between two states' cycles, using the measure:

$$
I_{j, k}=T^{-1}\left\{\sum_{t=1}^{T} S_{j t} S_{k t}+\left(1-S_{j t}\right)\left(1-S_{k t}\right)\right\}
$$

where $S_{j t}$ represents the business cycle phase of state $j$ at time $t$ (1 represents expansion, 0 contraction). This measure ranges between 0 and 1 , with 0 representing perfectly counter-cyclical business cycles, and 1 perfectly synchronous cycles. For two cycles described by a random walk, the measure will be 0.5 in the limit.

Table 2: Degree Of Concordance Between Classical State Cycles

State Final Demand

\begin{tabular}{lcccccc}
\hline & NSW & Victoria & Queensland & WA & SA & Tasmania \\
\hline NSW & 1.00 & & & & & \\
Victoria & 0.82 & 1.00 & & & & \\
Queensland & 0.81 & 0.82 & 1.00 & & & \\
WA & 0.81 & 0.77 & 0.76 & 1.00 & & \\
SA & 0.74 & 0.68 & 0.64 & 0.69 & 1.00 & \\
Tasmania & 0.72 & 0.70 & 0.66 & 0.61 & 0.78 & 1.00 \\
Australia & 0.92 & 0.91 & 0.81 & 0.87 & 0.69 & 0.69 \\
Average & $\mathbf{0 . 7 8}$ & $\mathbf{0 . 7 6}$ & $\mathbf{0 . 7 4}$ & $\mathbf{0 . 7 3}$ & $\mathbf{0 . 7 1}$ & $\mathbf{0 . 6 9}$ \\
\hline
\end{tabular}

Note: $\quad$ Average concordance is calculated over state-state concordances, excluding the concordance with Australia. 
The degree of concordance between each cycle is shown in Table 2. At first glance, these results portray a high degree of synchronicity, with most values around 0.7 or above. However, some care must be taken in interpreting these figures. Expansions in each state have a high degree of persistence, as a result of trend growth being positive, and the expected value for each coefficient is therefore greater than 0.5 ; in most cases, the expected value is somewhat above 0.6. ${ }^{9}$

Furthermore, it is important to remember the statistical error associated with our estimates, particularly given the small sample size we are working with. Using a test statistic proposed by McDermott and Scott (2000), we find that 11 of the 21 concordance measures in Table 2 are significant at the 5 per cent level, and 15 at 10 per cent. ${ }^{10}$ Tests involving at least one of NSW, Victoria and Western Australia tend to be significant, while very few relationships involving South Australia are significant, even at the 10 per cent level. ${ }^{11}$ We take these results to be quite strong evidence in favour of co-movement, given that our small sample size creates quite stringent tests of significance.

\subsection{Why state cycles might co-move: preliminary observations}

Given the considerable evidence presented in the previous section about the extent of co-movement, it is natural to ask what might explain this. As mentioned in Section 2, co-movement can be created by either common shocks or spillovers of idiosyncratic shocks, while idiosyncratic shocks themselves tend to reduce comovement.

High correlations between activity in one state and lagged activity in another would serve as prima facie evidence that spillovers may be a more important

9 The expected value is calculated by replacing $S_{i t}$ in Equation (1) with the proportion of time each series spends in expansion. Denoting this average proportion as $\bar{S}$, the expected value will equal $E\left(I_{j, k}\right)=\bar{S}_{j} \bar{S}_{k}+\left(1-\bar{S}_{j}\right)\left(1-\bar{S}_{k}\right)$ (Harding and Pagan 2002). The closer $\bar{S}_{j}$ and $\bar{S}_{k}$ are to 0.5 , the closer the expected value will be to 0.5 .

10 The test relies on the ratio of the drift of a series (i.e. its trend growth) to its standard error, as well as the sample size. The coefficients weighting these variables were found using Monte Carlo simulations, and are presented in McDermott and Scott (2000).

11 South Australia is included in all but two of the insignificant relationships at 10 per cent. 
source of co-movement than common shocks, which in our framework affect all states at the same time. ${ }^{2}$ Accordingly, Figure 5 shows a scatter plot of contemporaneous and lagged correlations, with observations above the 45-degree line representing state-pairs where the lagged correlation exceeds the contemporaneous correlation, indicative of a greater role for spillovers.

\section{Figure 5: Scatter-plot of Contemporaneous and Lagged Correlations}

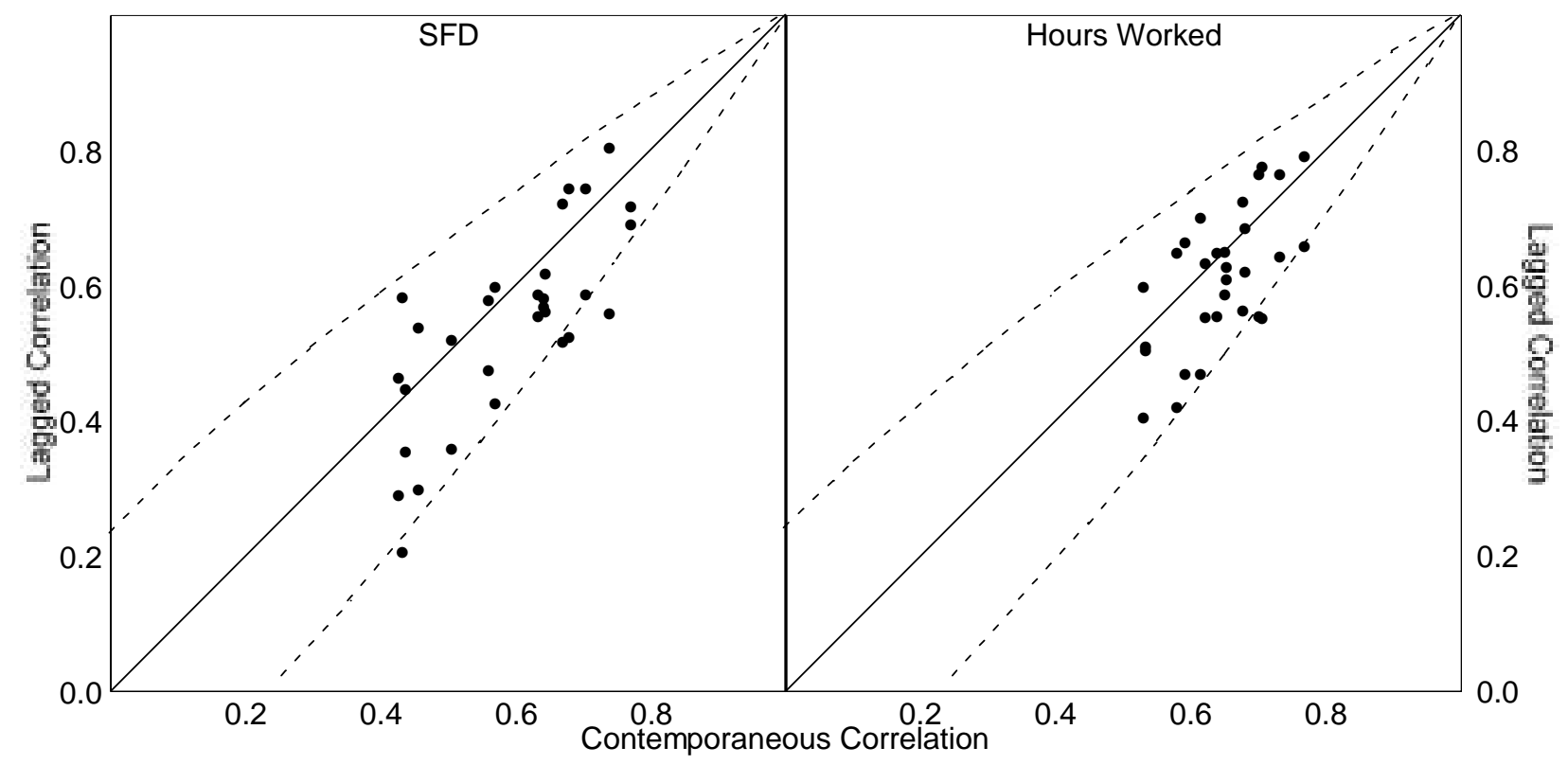

Note: Dotted lines are explained below, and are included only as a rough guide to 95 per cent confidence intervals. Contemporaneous correlations are shown on the x-axis, and lagged correlations on the y-axis.

Conducting a formal test of whether the lagged correlations are significantly different from the contemporaneous ones is not a straightforward task, since it involves making assumptions about the behaviour of the underlying data. As a rough guide, the dotted lines in Figure 5 depict the 95 per cent confidence bounds which would be obtained if (together with a number of other assumptions) the cycle data for state pairs came from a bivariate normal distribution with no serial correlation. ${ }^{13}$ While not a realistic assumption, these confidence intervals provide a

12 As discussed in Section 2, we distinguish common shocks from idiosyncratic shocks and spillovers by defining common shocks as those which affect all states in the same quarter. This identification assumption is discussed in further detail in Section 4.

13 This assumption implies that state cyclical activity is not correlated over time, which is clearly not the case. To obtain realistic confidence intervals, we would need to make assumptions about the underlying data generating process of each series. We take this type of modelling approach in Section 4. 
very broad indication that few of the lagged correlations are likely to be significantly greater than the contemporaneous correlations. This suggests that common shocks may be more important in driving co-movement than spillovers. A possible exception to this is Western Australia, whose lagged activity tends to be more highly correlated with contemporaneous activity in other states, indicating that Western Australia's resource-based economy might tend to lead activity in other states. This might occur in several ways. Because of its openness, movements in exchange rates or the terms of trade may affect Western Australia more quickly than other states. In addition, the capital-intensive nature of the mining sector in WA might result in demand-side shocks for WA's resources being transmitted to other states, as the need for mining-related capital rises or falls.

Granger causality tests are a second method that can provide guidance on the extent to which spillovers might drive co-movement. A finding that one state Granger-causes another (but not vice versa) would suggest that shocks from that state may indeed spill over to other states. Consequently, we tested for the presence of Granger causality between states, and between each state and the national cycle excluding that state. To account for the presence of unit roots in our series, both SFD and hours worked were first-differenced prior to testing.

The results found only four of the 30 state-state pairs indicated Granger causality at the five per cent level of significance using SFD, and nine using hours worked, with no evident pattern in the significant relationships. The higher number of significant relationships using hours worked may reflect that measure's inclusion of the traded sector. However, even taking the results using hours worked as more indicative of state interactions, these results suggest that spillovers play only a small role in driving co-movement, providing support to our earlier findings based on lagged correlations.

Before moving to a more formal examination of the sources of co-movement, it is worth mentioning the role that industrial structure may play in creating cyclical comovement. It has traditionally been assumed that, as part of the transmission mechanism of shocks to economic activity, industrial structure is important for comovement. Recent research, however, has tended to suggest otherwise (Clark and Shin 2000). Comparing Krugman's (1991) industrial dissimilarity index for state pairs with correlations between state cycles, we also find little evidence that 
industrial structure is important. Details of this analysis are presented in Appendix A. Consequently, we have chosen not to further explore industrial structure in our formal examination of the factors accounting for business cycle comovement.

\section{An Unobserved Components Model}

\subsection{Background}

The methods considered in the previous sections offer an insight into the patterns of cyclical activity in Australia, the degree of co-movement between state cycles, and the possible importance of different types of shocks. These simple measures may explain the extent to which economic activity in one state co-moves with activity in another, but they cannot determine how states respond to different types of shock, or where these shocks come from. They may also give an exaggerated impression of the economic interdependence of states, to the extent that state data contain a large component of activity common to all states and driven by external factors. Finally, the smoothness of the band-pass filtered data may lead to higher correlations than is plausible. In this section we introduce an unobserved components model, which attempts to disentangle the many sources of cyclical fluctuation, and determine how these fluctuations trace their way through the economy..$^{14}$

Our approach is a variation on that used by Kouparitsas (2002), which in turn is based on work by Watson (1986). In his analysis of US regional activity, Kouparitsas used quarterly per capita income from 1961:Q1 to 2000:Q4. Unfortunately, quarterly SFD for Australia is only available back to the mid 1980s, yielding around 70 observations. Given the number of parameters to be estimated, we reconfigure the model to use both SFD and hours worked simultaneously. The benefits of this adjustment are twofold. First, by restricting SFD and hours worked to respond (in the latter case with a lag) to the same common and state-specific cycles, we increase the degrees of freedom by doubling the number of observations

${ }^{14}$ There are a number of other popular models for business cycle co-movement; a short survey of these is provided in Appendix B. We tried two alternative modelling approaches but, as described in that appendix, these proved unworkable with our small sample. 
while less than doubling the number of coefficients. Second, the augmented model produces extracted cycles which can be considered a compromise between the fluctuations in labour market and income-based measures of activity (with hours worked also capturing developments in the traded sector, which SFD excludes). This compromise is consistent with Burns and Mitchell's definition of business cycles as patterns observed across a range of economic data, and hopefully adds stability to our results.

Data on state final demand and hours worked for the six states are available quarterly from 1985:Q4 to 2003:Q4. Growth in domestic final demand has its highest correlation with total hours worked growth at a lag of two quarters, so we lag SFD by two quarters in the model. ${ }^{15}$ This reduces the sample to 1985:Q4 2003:Q2, or 71 observations.

\subsection{Specification}

This section outlines the methodology and basic structure of the model. Details on the precise form and implementation of the model can be found in Appendix C. We assume the level of state activity (for either SFD or hours worked) can be characterised as the sum of state-specific trend and cyclical components:

$$
y_{i t}=\tau_{i t}+c_{i t}
$$

where $y_{i t}$ is the $\log$ of either measure of activity in state $i$, and $\tau_{i t}$ and $c_{i t}$ are statespecific trend and cycle components. Following Beveridge and Nelson (1981), we assume that the trend level of activity is characterised by a random walk with drift, as shown in Equation (3). ${ }^{16}$

$$
\tau_{i t}=\delta_{i}+\tau_{i t-1}+\mu_{i t}
$$

The drift parameter $\delta_{i}$ is state-specific, allowing states to grow at different trend rates. Although not shown in Equation (3), we add a structural break in the trend

\footnotetext{
${ }^{15}$ A lag of roughly two quarters is also apparent from a visual comparison of the band-pass filtered cycles for SFD and hours worked (Figure 2).

${ }^{16}$ Tests indicated the presence of a unit root in all states for both SFD and hours worked. We therefore model activity as the sum of a non-stationary trend and a stationary cycle.
} 
growth rate after 1994:Q4, to capture structural changes in the economy following the recession. ${ }^{17}$ The cyclical component for state $i$ is assumed to be driven by two unobservable cycles: a common national cycle, $x_{n t}$, and an idiosyncratic cycle, $x_{i t}$, as shown in Equation (4).

$$
c_{i t}=\gamma_{i} x_{n t}+x_{i t}
$$

The parameter $\gamma_{i}$ governs the magnitude of the response of activity in state $i$ to the common cycle, and is allowed to vary across states. This means that the amplitude of the common cycle effect on each state's activity may vary, but its shape and timing is identical for all states. The common cycle is assumed to be an $\operatorname{AR}(1)$ process: ${ }^{18}$

$$
x_{n t}=\rho x_{n t-1}+\eta_{t}
$$

where $\eta_{t}$, the common shock, is normally distributed with mean zero and variance $\sigma_{n}^{2}$. The idiosyncratic cycles are modelled as a VAR, with each idiosyncratic cycle specified as a function of the first lags of all six idiosyncratic cycles:

$$
x_{i t}=\left(\sum_{j=1}^{6} \phi_{i j} x_{j t}\right)+\varepsilon_{i t}
$$

where the $\varepsilon_{i t}$, the state-specific (or idiosyncratic) shocks, are normally distributed with mean zero and variance $\sigma_{i}^{2}$. Idiosyncratic shocks in each period are assumed to be uncorrelated both across states and with the common shock. We assume that all shocks are uncorrelated across time.

${ }_{17}$ We experimented with various locations for the trend break, and a break after the 1990 recession was found to be most successful in fitting the data and ensuring the estimated cycles were stationary. Our results are not sensitive to the exact location of the break, but we chose the end of 1994 as a point sufficiently past the end of the recession period yet close to the middle of our sample.

${ }_{18}$ In his paper, Kouparitsas specified the common cycle as an AR(2) process. Using an AR(2) in our model, one coefficient estimate is greater than one and the other is a small negative number, with the two summing to about 0.95 . The estimated coefficient obtained from an $\mathrm{AR}(1)$ is also around 0.95 , so we use an $\mathrm{AR}(1)$ for parsimony. 
Note that, in this framework, idiosyncratic and common shocks are distinguished by the fact that common shocks affect all states simultaneously, while idiosyncratic shocks affect only the state of origin in the quarter of the shock. Idiosyncratic shocks may subsequently spill over to other states' cycles, however. Our framework therefore allows for three sources of cyclical disturbance to the level of state activity: common shocks, idiosyncratic shocks, and spillovers of shocks between states.

Because all series are non-stationary, we model SFD and hours worked in first differences. The estimated equations (for each state $i$ ) are:

$$
\left[\begin{array}{c}
\Delta s_{i t-2} \\
\Delta h_{i t}
\end{array}\right]=\left[\begin{array}{c}
\delta_{i}^{s} \\
\delta_{i}^{h}
\end{array}\right]+\left[\begin{array}{cc}
\gamma_{i}^{s} & 1 \\
\gamma_{i}^{h} & \theta_{i}
\end{array}\right]\left[\begin{array}{c}
\Delta x_{n t} \\
\Delta x_{i t}
\end{array}\right]+\left[\begin{array}{c}
\mu_{i t}^{s} \\
\mu_{i t}^{h}
\end{array}\right]
$$

where the superscripts $s$ and $h$ denote coefficients pertaining to SFD and hours worked. Note that SFD and hours worked respond to the same common and idiosyncratic cycles, albeit with different parameters. ${ }^{19}$ The variables $\mu_{i t}$ are error terms, containing the trend innovations and noise (such as measurement error) not captured by the common or idiosyncratic cycles. These errors are assumed to be normal with zero mean and constant variance. All error terms in the model are assumed to be independent across time, states and equations. We estimate the system of Equations (5), (6) and (7) simultaneously using a Kalman filter. ${ }^{20}$

\section{Modelling Results}

It is important to emphasise that our model results must be interpreted with caution, given the limited amount of data available and the well-known sensitivity of Kalman filters to assumptions and initial conditions. Thus our focus here is on the patterns of behaviour of the common, idiosyncratic and spillover components, and the stylised facts arising from these, rather than on the precise coefficient

19 The parameters $\gamma_{i}$ and $\theta_{i}$ allow SFD and hours worked for each state to respond with different amplitudes to the common and their own idiosyncratic cycles. For identification purposes, SFD is assumed to respond one-for-one to its idiosyncratic cycle, and $\gamma_{1}^{s}$ (the responsiveness of New South Wales SFD to the common cycle) is set equal to one.

20 The programs used to estimate the model are available from the authors upon request. 
estimates and quantitative implications of the model. While we believe the model provides a fair representation of the data, there is simply not enough historical information on Australian state activity to draw reliable quantitative conclusions. Bearing this caveat in mind, however, the model results appear to support the findings we reported in Section 3, providing evidence that common shocks, rather than spillovers of lagged shocks between states, are most responsible for the observed co-movement of state cycles. We focus here on the results for SFD; the results for hours worked are quite similar and are provided in Appendix D.

\subsection{State Final Demand and Hours Worked}

The estimates for $\delta$, in the first two columns of Table 3, suggest that trend growth in SFD picked up in all states during the 1990s, in some cases substantially. ${ }^{21}$ This accords with our priors: the period since the recession has seen higher average productivity growth nationally, and stronger growth in every state.

\begin{tabular}{|c|c|c|c|}
\hline \multicolumn{4}{|c|}{ Table 3: Estimated Parameters for SFD } \\
\hline \multirow[b]{2}{*}{ State } & \multicolumn{2}{|c|}{ Trend parameter, $\delta_{i}^{s}$} & \multirow{2}{*}{$\begin{array}{c}\text { Common cycle } \\
\text { response parameter, } \gamma_{i}^{s}\end{array}$} \\
\hline & 1985:Q4 - 1994:Q4 & 1995:Q1 - 2003:Q2 & \\
\hline New South Wales & 2.59 & 3.61 & 1 \\
\hline Victoria & 1.68 & 4.76 & 1.06 \\
\hline Queensland & 3.81 & 4.47 & 1.19 \\
\hline Western Australia & 3.18 & 4.16 & 1.36 \\
\hline South Australia & 1.59 & 3.63 & 1.15 \\
\hline Tasmania & 1.43 & 2.33 & 1.19 \\
\hline National average & 2.51 & 4.09 & 1.10 \\
\hline $\begin{array}{ll}\text { Jotes: } & \text { Trend paramete } \\
& \text { national cycle } r \\
& \text { calculated as the }\end{array}$ & ef the state figures, & ted by their share of tot & $\begin{array}{l}\text { ntage trend growth rates. The } \\
\text { 'national average' figures are } \\
\text { SFD. }\end{array}$ \\
\hline
\end{tabular}

We begin our analysis of the estimated cycles with the common cycle, which influences activity in all states. Recall that the extent to which SFD in state $i$

${ }^{21}$ In contrast, the estimated post-break trend growth rates for hours worked are all lower than the pre-break estimates. This suggests productivity growth in all states must have increased substantially during the 1990 s, to reconcile the slowing of growth in hours worked with the increased trend growth rates of SFD. 
responds to the common cycle is governed by the parameter $\gamma_{i}^{s}$, so the magnitude of the common cycle effect varies across states. Figure 6 shows the estimated common cycle multiplied by the weighted average of the parameters $\gamma_{i}^{s}$, where the weights are the states' shares of total SFD. This can be thought of as the common cycle of all states combined, or the common component of domestic final demand, excluding final demand in the two territories.

Figure 6: Weighted Average Common Cycle

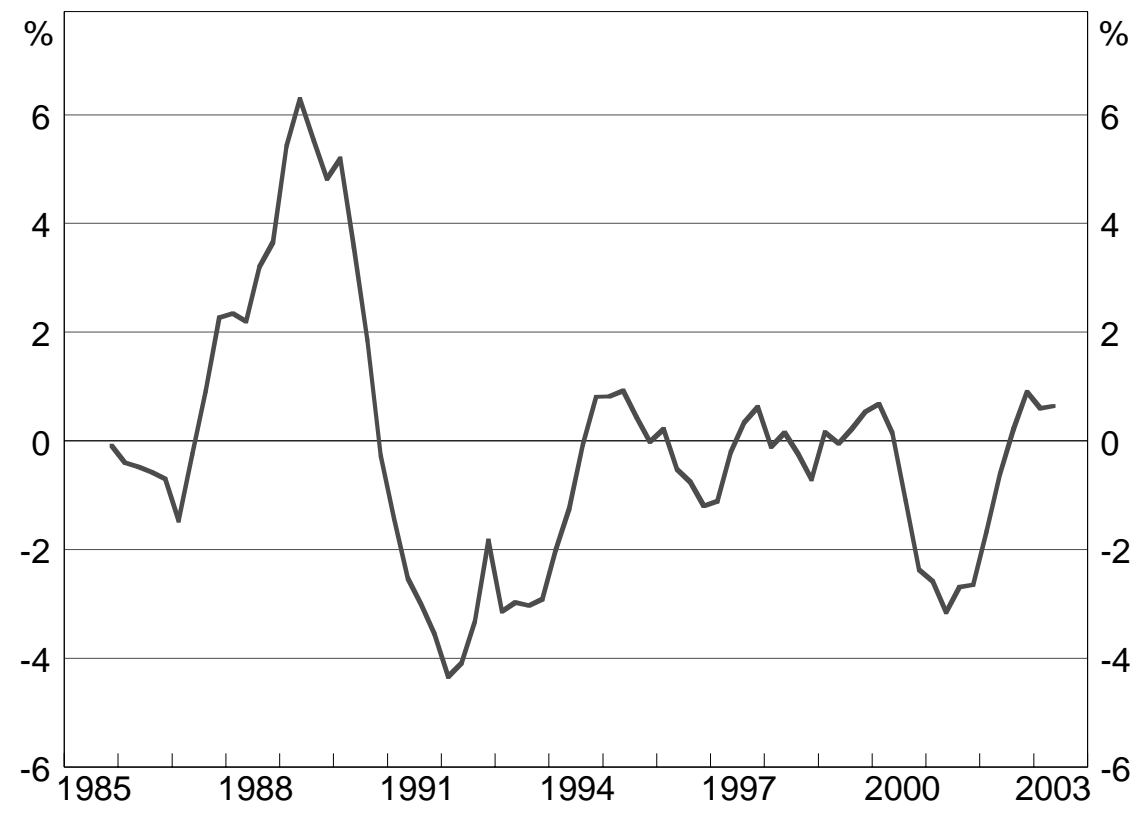

Note: Graph depicts the weighted average common cycle for SFD across states, where the average is calculated using states' shares of total SFD as the weights.

Although the estimated common cycle should be interpreted with our earlier caveat in mind, it matches many of the stylised facts about the Australian business cycle over the last 20 years. ${ }^{22}$ The property and investment boom in Australia in the late 1980s led to a strong common cyclical upswing in economic activity, which peaked in 1989 before the economy fell into recession the following year. This is reflected in the estimated cycle, which peaks six per cent above trend in June 1989 before subsequently falling to levels indicating below-trend activity. ${ }^{23}$ The cycle remains negative until mid 1994, before settling around zero over the remainder of the 1990s. (Note that this near-zero level does not imply weak growth, but rather

\footnotetext{
${ }^{22}$ The estimated cycle has a correlation of 0.85 with actual domestic final demand (detrended using a Hodrick-Prescott filter).

${ }^{23}$ This coincides with the peak in the dated Australian SFD cycle discussed earlier.
} 
less volatile growth at a stronger trend rate.) The final major feature is a dip below trend in late 2000, consistent with the swings in housing construction associated with the introduction of the GST in July 2000. Current conditions indicated by the model can be characterised as around trend.

Estimates of the responsiveness of states to the common cycle for SFD, $\gamma_{i}^{s}$, are presented in the last column of Table 3. ${ }^{24}$ While these estimates should be interpreted with the usual caution, the degrees of responsiveness of different states to the common cycle generally accord with our priors and with previous research. The estimated response coefficients are similar for all states, suggesting that the common cycle has quite a uniform impact. Nevertheless, there appears to be a tentative relationship between openness and degree of sensitivity to the common cycle. Western Australia, which has the most open economy and is therefore most exposed to exchange rate shocks (Weber 2003, page 2), also has the strongest response. The two least open states, New South Wales and Victoria, are the least responsive, consistent with the idea that fluctuations in the exchange rate and the terms of trade are major types of common shock for a small open economy. Economies with greater openness would be expected to be more sensitive to these shocks than less open economies.

In addition to the effect of the common cycle, the overall cycle in each state is partly driven by fluctuations specific to that state, which are captured in its idiosyncratic cycle, as shown in Equation (4). ${ }^{25}$ Recall from Equation (4) that each state's cycle consists of a common and an idiosyncratic part. One way of determining the relative importance of common and idiosyncratic shocks to state cyclical activity is to compare the contributions of the two terms on the right hand side of Equation (4) to each state's overall cycle, $c_{i t}$.

${ }^{24}$ The estimated coefficients for hours worked are around half the size, with an average coefficient of 0.52 (compared to an average of 1.10 for SFD).

25 Each state's SFD is assumed to respond one-to-one to its idiosyncratic cycle. Similarly to the common shock, we constrain hours worked to respond to the same idiosyncratic cycle as SFD, but allow the magnitude of response to vary by the scaling parameter $\theta$. These fluctuations are not required to be totally uncorrelated with fluctuations in other states in the same time period. Rather, we separate the idiosyncratic cycle from the common cycle by defining the latter as affecting all states simultaneously. Hence a regional shock covering more than one state would be picked up in those states' idiosyncratic cycles rather than in the common cycle. 
Figure 7 shows each state's overall cycle, graphed as a line, with the bars representing the common and idiosyncratic contributions to the overall cycle. In all states, the common cyclical component tends to be more important than the idiosyncratic component. Table 4 summarises the contributions of these components to the variance of the overall cycles. The contribution of the common cycle tends to be greater for the larger states, while for the smaller states the contributions of both components are quite similar.

\begin{tabular}{lcc}
\hline \multicolumn{3}{c}{ Table 4: Variance Decomposition Of Cyclical Components } \\
State Final Demand
\end{tabular}

Since idiosyncratic shocks appear to be more important for the smaller states (WA, SA and Tasmania), we might conclude that this reflects fundamental behavioural differences between states. This conclusion may be unwarranted, however. The model actually finds that the smaller states are more sensitive to the common cycle than their larger counterparts (see the last column of Table 3). Hence the smaller states receive, if anything, a greater common cycle effect than the larger states, but also have bigger idiosyncratic cycles. One possible explanation for this is that exchange rate and other external shocks may in practice affect states with different lags. If this were the case, only part of these shocks would be treated as a common shock and the rest would flow into each state's idiosyncratic cycle. From Figure 7, states for which this might be important are WA (whose overall cycle leads the common cycle), and SA (whose overall cycle lags the common cycle). The prominence of idiosyncratic cycles in these states may thus reflect the difficulties inherent in allocating shocks, rather than implying a greater role for shocks we tend to think of as region-specific (such as localised droughts or state fiscal initiatives). 
Figure 7: State Cycle Decompositions

State Final Demand

New South Wales

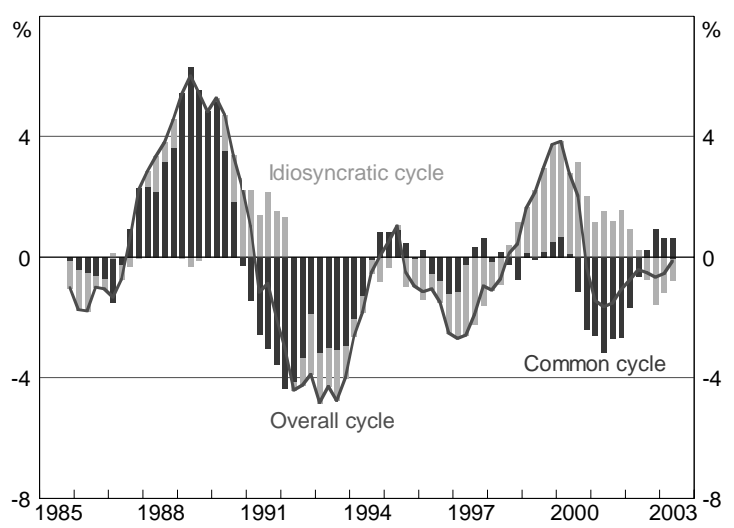

Queensland

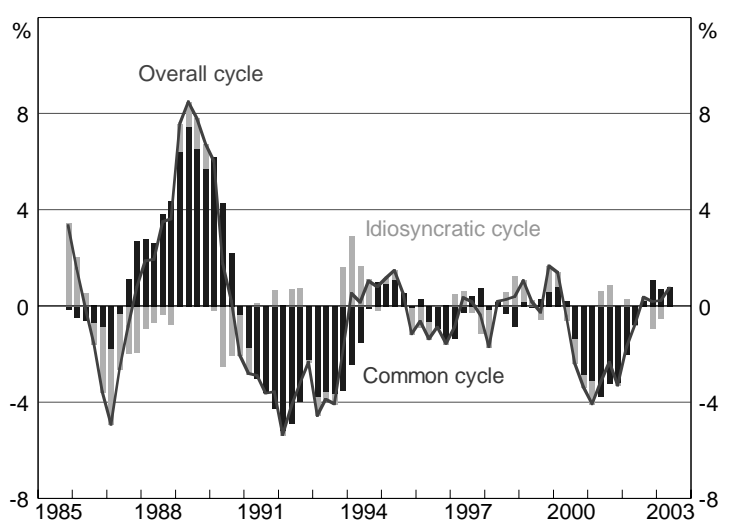

South Australia

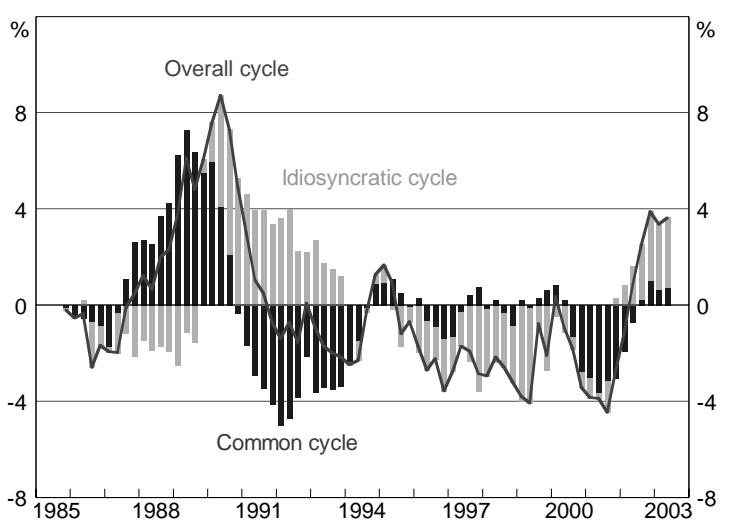

Victoria

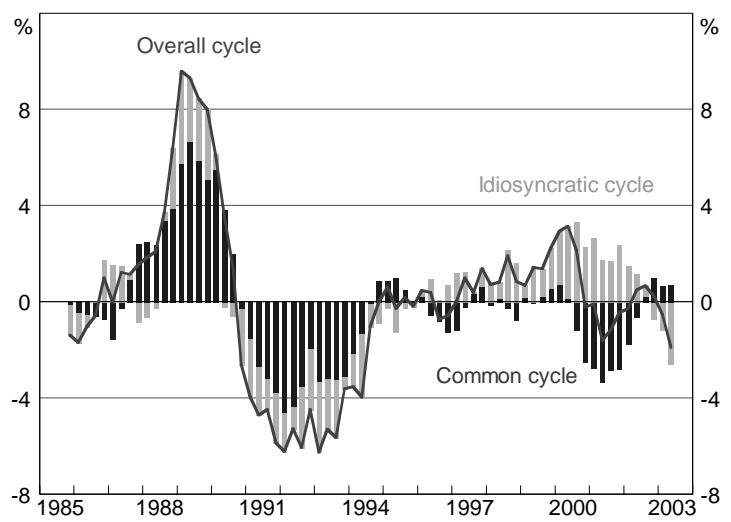

Western Australia

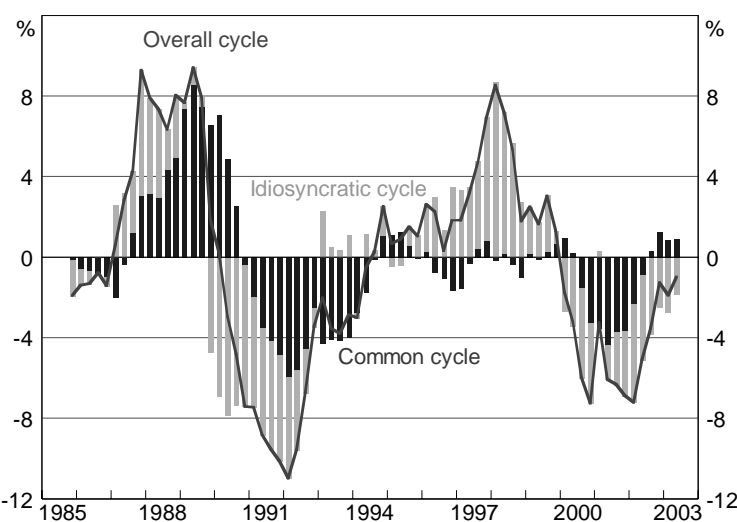

Tasmania

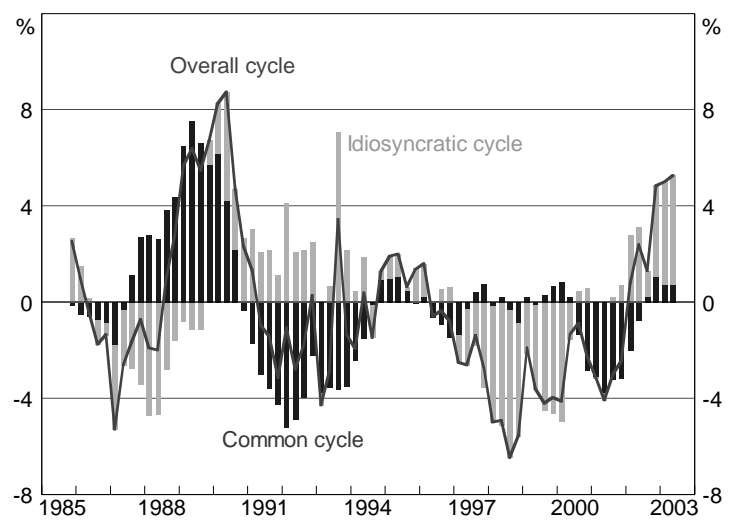


These results suggest that common shocks are the primary contributors to cycles in state activity, although idiosyncratic shocks also play an important role. The fact that idiosyncratic shocks appear to make a larger contribution to activity in the smaller states could reflect behavioural differences, but we feel it is more likely to be explained by differences in the timing of states' responses to shocks such as exchange rate fluctuations.

Finally, we turn to spillovers as a third source of fluctuations in state activity. To assess the role and behaviour of spillovers in the model, we examine the impulse response functions implied by Equation (6), which trace the effect over time of a one per cent shock to one state's idiosyncratic cycle on the cycles of the other states. These impulse response functions are presented in Figure D1 of Appendix D. Unfortunately the functions are not well-behaved, primarily because the estimated response coefficients for WA and, to a lesser extent, Queensland cause them to respond with implausible strength to shocks in other states. For example, shocks to NSW have a negative and destabilising influence on WA's activity, with a one percentage point shock to NSW's cycle reducing activity in WA by 4.7 per cent in the first year alone. (We could find no outliers in the data to explain these large coefficients; as before, they may arise in part from differences in the timing of state responses to shocks like fluctuations in the exchange rate.) The other states' responses are also then contaminated, to some extent, through flow-on effects. These problems appear to stem from the small sample available and the complexity of the model, which make it especially difficult to accurately estimate the feedback effects between state idiosyncratic cycles. ${ }^{26}$

We can overcome some of the problems with the model's short-run dynamics, and better understand the relative impact of common and idiosyncratic shocks, by focussing instead on the longer-term cumulative effects of cyclical shocks on activity. The first six columns in Table 5 show the cumulative gain in SFD for each state (analogous to a 'change in wealth' measure) in the eight quarters following a temporary one per cent shock to one state's idiosyncratic cycle. In the last column

${ }^{26}$ To mitigate the problem somewhat, we also calculate impulse responses from the estimated coefficients, but with the response coefficients for WA and Queensland set to zero. This is equivalent to 'disconnecting' these two states from the system, so they do not respond to shocks in other states. The resulting impulse response functions (Table D2) are much more sensible. However, they are generally quite small and unlikely to be statistically significant. 
of Table 5, we present the cumulative responses of state activity following a similar shock to the common cycle.

\section{Table 5: Cumulative Responses to Shocks}

State Final Demand

\begin{tabular}{lcccccc|c}
\hline & \multicolumn{6}{c}{ Cumulative effect after eight quarters of a shock to: } \\
\cline { 2 - 8 } State & NSW & VIC & QLD & WA & SA & TAS & National \\
\hline New South Wales & $\mathbf{4 . 5}$ & -1.0 & -1.1 & -0.6 & -1.1 & -1.2 & 5.9 \\
Victoria & 1.1 & $\mathbf{1 . 8}$ & -1.0 & 0.1 & -2.8 & -0.6 & 6.3 \\
Queensland & 1.7 & 0.3 & $\mathbf{2 . 5}$ & 1.6 & 1.3 & 1.1 & 7.1 \\
Western Australia & -8.6 & -2.7 & -1.8 & $\mathbf{2 . 2}$ & -2.7 & -0.8 & 8.0 \\
South Australia & 1.8 & 1.0 & 0.7 & -1.3 & $\mathbf{3 . 8}$ & 0.5 & 6.8 \\
Tasmania & 2.2 & 2.4 & 2.4 & -0.4 & 3.3 & $\mathbf{3 . 1}$ & 7.1 \\
\hline
\end{tabular}

Notes: The cumulative response is effectively the integral between the shocked level of SFD and the no-shock counterfactual level from the shock quarter to the eighth quarter following the shock. The shocks to state idiosyncratic cycles are all 1.0 per cent. The shock to the common cycle is 0.91 per cent, which corresponds to an increase in aggregate final demand of one per cent in the shock quarter. (The shock applied is less than one per cent because the average state response to the common cycle is greater than one.) All shocks last one quarter, but the model dynamics imply a sustained decay path in each case.

As with the impulse responses, the results for WA (in the fourth row) seem unrealistic. Aside from these, however, the most striking features are the cumulative effects of common shocks on activity, and the uniformity of these effects across states. The effect of a one per cent shock to the common cycle accumulates to an increase of between 5.9 and 8 per cent in the level of SFD in each state over the shock quarter and the subsequent eight quarters. The size of this effect is due to the strong persistence of the common cycle, implying that common shocks provide repeated gains (or losses) in activity over a long period.

The diagonal elements of the first six columns, measuring the long-term effect of idiosyncratic shocks on the state of origin, are also quite large (well above the initial shock of one per cent), although significantly smaller than the common shock effects. The off-diagonal elements, which characterise spillovers of shocks between states, are generally smaller than the corresponding own-state effects and in some cases have the opposite sign. ${ }^{27}$ These results broadly support our earlier

27 The exceptions are: the figures for WA (which, as already discussed, we regard as unreliable); those for Tasmania (which may reflect its relatively small size); and the response of Victoria to SA, which also appears to be an outlier. 
findings: common shocks appear the most important to activity, followed by idiosyncratic shocks, with spillovers playing a relatively minor role. As before, however, we stress that it is difficult to obtain more than a general sense for the relative relationships between idiosyncratic cycles given the complexity of the model and the data available. The issues surrounding WA's coefficient estimates, in particular, reinforce this caveat.

\subsection{Gross State Product and Hours Worked}

So far we have used SFD as our proxy for state output. As discussed earlier, SFD effectively excludes trade and changes in inventories, yet trade flows might be expected to capture the bulk of spillover effects between states. It would be preferable to use a measure of gross state product (GSP), which captures these effects. Since the ABS ceased calculating and reporting quarterly GSP estimates in June 1997, we construct our own estimates of quarterly GSP from annual data, to assess whether including trade increases the role given to spillovers in the model.

We apply the ordinary least squares method detailed in Chow and Lin (1971), using the quarterly profile of SFD to interpolate quarterly GSP estimates from the ABS's annual GSP series. ${ }^{28}$ Compared to the ABS quarterly series, available over the period 1985:Q3-1997:Q2, the constructed series matches medium-term movements in GSP moderately well (year-ended growth rates of the two sets of estimates have correlations of about 0.7), but quarterly growth rates only marginally (correlations of around 0.3). Since the ABS emphasised the experimental nature of its constant price quarterly GSP estimates, there is no absolutely reliable benchmark, but we feel it is worth examining the effects of using our constructed measure of GSP in place of SFD in the model.

Full results are presented in Appendix D. The main point to note is that most of the results for this specification are very similar to those from the model using SFD

${ }^{28}$ This method involves estimating a simple linear regression of annual GSP on annual SFD, allowing for serial correlation in the error term. We then use the estimated coefficients to generate quarterly estimates of GSP from the quarterly SFD data. Finally, in order to satisfy an annual adding-up constraint, the serial correlation relationship is used to generate quarterly predictions of the error terms, which are added to the quarterly GSP predictions. Further details can be found in Chow and Lin (1971). The program used to generate the estimates is also available from the authors. 
and hours worked. The estimated common cycles of the two models are almost identical, and the trend and common cycle response parameter estimates for GSP (Table D6) are much the same as those for SFD. On the whole, the change does not appear to alter the main characteristics of the model. This may be due in part to the fact that the quarterly profiles of the constructed GSP series and SFD are by definition very similar.

The cumulative state responses to common and idiosyncratic shocks for the GSPhours worked model are presented in Table 6. Using GSP does not substantially alter our assessment of the importance of spillovers. The response of WA to NSW is much more reasonable than in Table 5, but its response to the national cycle is larger. Most of the other responses remain broadly the same size. The off-diagonal elements are larger than in Table 5, but not significantly larger. Except for Tasmania's response to NSW and WA's response to Tasmania, all of the offdiagonals are smaller than their diagonal counterparts. Once again, this suggests that spillovers are less important than idiosyncratic shocks, but may nevertheless be of some significance in determining activity.

Table 6: Cumulative Responses To Shocks

Gross State Product

\begin{tabular}{lcccccc|c}
\hline & \multicolumn{6}{c}{ Cumulative effect after eight quarters of a shock to: } \\
\cline { 2 - 8 } State & NSW & VIC & QLD & WA & SA & TAS & National \\
\hline New South Wales & $\mathbf{3 . 5}$ & -0.2 & -1.2 & -0.6 & -1.1 & -0.6 & 5.5 \\
Victoria & 1.7 & $\mathbf{3 . 0}$ & 0.0 & 0.0 & -1.5 & -0.8 & 5.6 \\
Queensland & 0.6 & 0.6 & $\mathbf{2 . 8}$ & 1.5 & 0.7 & 1.4 & 7.2 \\
Western Australia & 1.4 & 2.8 & 2.9 & $\mathbf{3 . 7}$ & 2.4 & 4.2 & 9.6 \\
South Australia & -2.6 & -1.9 & -1.6 & -1.5 & $\mathbf{2 . 1}$ & -2.3 & 5.6 \\
Tasmania & -3.9 & -2.7 & -1.2 & -1.3 & 0.0 & $\mathbf{1 . 3}$ & 4.4 \\
\hline
\end{tabular}

Notes: The cumulative response is effectively the integral between the shocked level of GSP and the no-shock counterfactual level from the shock quarter to the eighth quarter following the shock. The shocks to state idiosyncratic cycles are all 1.0 per cent; the shock to the common cycle is 0.89 per cent (see notes to Table 5). All shocks last one quarter, but the model dynamics imply a sustained decay path in each case.

On the whole, using an approximate measure of GSP in place of SFD in our model does not appear to change our earlier conclusions. Gauging the precise details of the effects of spillovers remains very difficult given the approximate nature of our GSP estimates and the small sample size. 


\section{Conclusion}

Our goal in this paper has been to try to disentangle the common and idiosyncratic fluctuations which drive state cyclical activity in Australia, and to trace their paths through the economy. We have used a variety of statistical techniques to achieve this. A number of common conclusions arise from the different techniques. State business cycles tend to co-move quite strongly, particularly those of the larger states (New South Wales, Victoria and Queensland). This is perhaps not surprising, given all states share a common monetary policy and exchange rate. Correlations between state business cycles (using SFD as a measure of activity) are similar to those found in regional studies of other countries, and suggest the presence of a significant contemporaneous relationship. Concordance measures and comparisons of recession periods both support these findings.

A more detailed analysis suggests that this co-movement arises mainly from a pronounced common cycle, which affects all states simultaneously. This common cycle is presumably driven by macroeconomic shocks such as fluctuations in the exchange rate or the terms of trade. Spillovers of idiosyncratic shocks from one state to another through trade and investment linkages appear less important in explaining co-movement. Lagged correlations between state cycles are generally smaller than contemporaneous correlations, and there is only modest evidence that cyclical activity in one state Granger-causes activity in other states.

Using an unobserved components model, we find evidence that common shocks play the major role in shaping state activity, followed by idiosyncratic shocks, with spillovers of shocks between states the least important. Idiosyncratic shocks may play a relatively greater role in shaping the cycles of the smaller states, but simulations of shock responses suggest that the cumulative impact of a common shocks is larger (even in these states) than an idiosyncratic shock of comparable size. Overall, while the lack of a long time series of state data makes it difficult to be definitive, our various approaches all suggest that state business cycles move quite closely together in Australia, and that common shocks are the most important source of fluctuations in state economic activity. 


\section{Appendix A: Industrial Structure and Cyclical Co-Movement}

Whilst it has traditionally been assumed that industry structure is an important determinant of cyclical co-movement, recent research has tended to suggest otherwise (Altonji and Ham 1990; Clark and Shin 2000). A simple test of the importance of industry structure for cyclical co-movement is to construct a measure of the industrial similarity of state pairs, and compare this with the correlation of their cyclical activity. We use Krugman's (1991) index of industrial dissimilarity, as shown in Equation (8), which increases from 0 to a maximum value of 2 as two economies become less similar.

$$
D I S S_{i j}=\sum_{m}\left|S_{m}^{i}-S_{m}^{j}\right|
$$

Here, $S_{m}^{i}$ and $S_{m}^{j}$ represent industry $m$ 's share of total factor income in state $i$ and $j$ respectively. A scatter-plot of this index against correlations in band-pass filtered SFD is presented in Figure A1.

\section{Figure A1: Industrial Dissimilarity and Correlations of SFD}

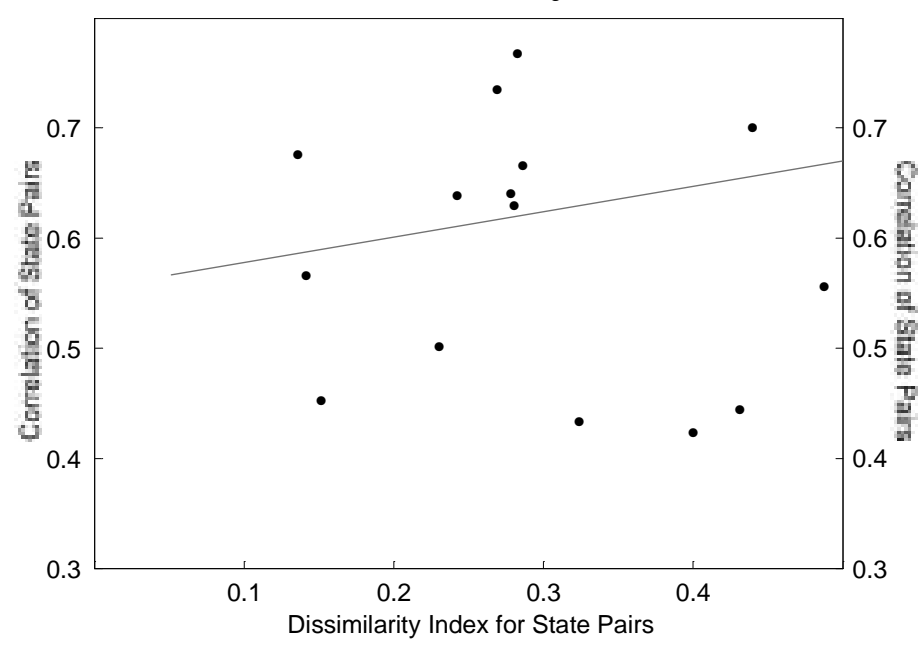

Note: Trend line calculated excluding Western Australian observations, as dissimilarity indices involving Western Australia significantly exceed those among other states.

The results show that there is little relationship between the two, as indicated by the poor fit of the trend line. Furthermore, the trend line is actually positively sloped, counter-intuitively indicating that co-movement actually increases with differences in industrial structure, rather than with similarity. This simple exercise suggests that there is little role for industrial structure in explaining co-movement among state business cycles. 


\section{Appendix B: Modelling Business Cycles}

The primary aim of most business cycle modelling is to decompose the level of economic activity into a trend component, and one or more cyclical components. One immediate problem is that there are many ways of detrending data, and it is often unclear a priori which is preferable in any specific case. To add to the difficulty, recent work (Canova 1998) has demonstrated that conclusions drawn from business cycle analysis can vary significantly depending on the detrending technique employed. Nevertheless, modelling output in terms of trend and cyclical components in order to understand the propagation of shocks through an economy remains an important goal, and in recent years most papers have taken one of two approaches.

The most common approach uses vector autoregression (VAR) techniques. Inspired by Burns and Mitchell's (1946) definition of the business cycle as a common underlying pattern across a range of data, researchers have modified the traditional VAR to isolate one or more common cycles (or factors) which drive activity across countries, regions or economic variables. ${ }^{29}$ Various methods have been used to extract these common factors from the detrended data. Labhard (2003) estimated a VAR for G7 activity, defining the average disturbance across countries in each time period as the common shock, and the remainder of the disturbance as a region-specific shock. Stock and Watson (2003) identify a common factor by imposing structural restrictions on the reduced-form errors. Techniques such as these have collectively become known as factor-structural VARs (FSVARs) and have been used to study regional co-movement in papers such as Carlino and de Fina (1995) and Carlino and Sill (1997).

The second approach, proposed by Watson (1986), is to estimate an unobserved components model, in which activity is influenced by unobservable common and idiosyncratic cycles. The researcher specifies the functional forms of the cycles, which are extracted from the observed data using a Kalman filter. The resulting parameter estimates offer an insight into the relationships between the cycles. The

\footnotetext{
${ }^{29}$ This methodology is not limited to studies of relationships between countries or regions. It has also been used to construct coincident indices of activity, by extracting a common cycle from a range of economic data for the one country or region. See, for example, Forni et al (2001).
} 
unobserved components model has recently been used in regional research by Rissman (1999), who looked at the co-movement of US regional employment cycles, and Kouparitsas (2002), who performed a similar exercise using per capita income for eight US regions.

In Sections 4 and 5 we used an unobserved components model to study cyclical comovement across Australian states. We also attempted to estimate a FSVAR model similar to Labhard (2003), but found it difficult to get significant results for the coefficient estimates given the small sample and volatility of the available data. The result was a very large error component, which caused the common cycle to completely dominate overall activity. Based on the sensitivity of our results to the noise component, we decided against using this approach. 


\section{Appendix C: Details on the Unobserved Components Model}

\section{Model structure}

The unobserved components model described in Section 4 comes from the class of general dynamic multiple-indicator, multiple-cause (DYMIMIC) models pioneered by Watson and Engle (1983). These models characterise observed economic activity as a function of observed and unobserved variables, both of which may interact dynamically. When specified in a state-space form, these models can be estimated using a Kalman filter and maximum likelihood procedure. Because of the complexity of our framework, we use Watson and Engle's EM algorithm to estimate the model. Further details on this procedure are given below.

We assume SFD (lagged two quarters) and hours worked for each of the six Australian states to be functions of an observed trend variable (which is assumed to be linear) and two unobserved cycle variables: a common cycle, and a statespecific cycle. In order to be correctly estimated, the variables in the model must all be stationary, so we model the equation in first differences of log levels.

In state-space form, the model has the following measurement equations:

$$
\left[\begin{array}{c}
\Delta s_{t-2} \\
\Delta h_{t}
\end{array}\right]=\left[\begin{array}{ll}
\delta_{1}^{s} & \delta_{2}^{s} \\
\delta_{1}^{h} & \delta_{2}^{h}
\end{array}\right]+\left[\begin{array}{cc}
\gamma^{s} & I_{6} \\
\gamma^{h} & \Theta
\end{array}\right]\left[\begin{array}{c}
\Delta x_{n t} \\
\Delta X_{t}
\end{array}\right]+\left[\begin{array}{c}
\mu_{t}^{s} \\
\mu_{t}^{h}
\end{array}\right]
$$

and transition equation:

$$
\left[\begin{array}{l}
x_{n t} \\
X_{t}
\end{array}\right]=\left[\begin{array}{ll}
\rho & 0 \\
0 & \Phi
\end{array}\right]\left[\begin{array}{l}
x_{n t-1} \\
X_{t-1}
\end{array}\right]+\left[\begin{array}{l}
\eta_{t} \\
\varepsilon_{t}
\end{array}\right]
$$

where $\Delta s_{t}$ and $\Delta h_{t}$ are $6 \times 1$ vectors of first-differenced (log) SFD and (log) hours worked for the six states in the period $t ; D_{t 1, t 2}$ is a dummy variable taking the value 1 when $t 1 \leq t \leq t 2$ and zero otherwise; $x_{n t}$ is the level of the common national cycle at time $t$; and $X_{t}$ is a $6 \times 1$ vector of the levels of the six state-specific cycles at time $t$. The parameters $\delta$ and $\gamma$ are all $6 \times 1$ vectors; $\Theta$ is a $6 \times 6$ diagonal matrix with coefficients $\theta_{i}$ on the diagonal governing the response of hours worked in state $i$ to 
its own state-specific cycle; $\rho$ is a scalar coefficient; and $\Phi$ is a $6 \times 6$ matrix of interaction coefficients for the idiosyncratic cycles. The series $\mu_{t}^{s}, \mu_{t}^{h}$ and $\varepsilon_{t}$ are $6 \times 1$ vectors of normally distributed, mean-zero errors, and $\eta_{t}$ is a $1 \times 1$ mean-zero normal disturbance.

In order to identify the model, we impose a number of restrictions. First, we normalise $\gamma_{1}^{s}$, the response of NSW SFD to the common cycle, to equal 1. Hence the responses of other states' SFD to the common cycle are relative to the NSW SFD response, as are the responses of hours worked in each state to the common cycle (governed by the parameters $\gamma^{h}$ ). Second, we normalise SFD in each state to respond one-to-one to its own state-specific cycle. Hours worked in each state respond to the same state-specific cycles as SFD, but the coefficients $\theta$ again allow the magnitudes of these responses to vary. Finally, we assume all disturbances are orthogonal to their own lags, and to the other disturbances in the model.

\section{Estimating the model}

To estimate the model we use the EM algorithm described in Watson and Engle (1983). Estimation involves finding values for both the parameters and the unobserved variables, $x_{n t}$ and $X_{t}$. As opposed to maximum likelihood estimation, which forms a likelihood function of the parameters and unobserved components, and seeks to maximise this, the EM algorithm splits the estimation of parameters and unobserved components into two separate stages. The procedure is iterative, alternating between the two stages until a desired level of convergence in the parameters and series is achieved..$^{30}$

The basic structure of the algorithm is as follows:

1. Initialise the parameters and state variables. The initial values for $\delta$ are given by the means of the dependent variables over the two subsamples (1985:Q41994:Q4 and 1995:Q1-2003:Q2). Cycles for each state are extracted by subtracting the implied trends from the levels of the dependent variables. In

${ }^{30}$ We impose a convergence criterion of $1 \times 10^{-4}$ on the sum of squared deviations of the parameters and unobserved components from their previous iteration levels. We found the results to be insensitive to the exact criterion and starting points used. 
each period, the mean of these cycles across states is designated as the common cycle for that period, and the residual for each state is that state's idiosyncratic cycle in the period. The other interaction parameters are then estimated using OLS. The state variables are then re-initialised to zero, as recommended by Hamilton (1994).

2. Estimate the state variables using the Kalman filter.

3. Re-estimate the parameters using OLS.

4. Evaluate convergence, and return to step 2 if convergence is not achieved. 


\section{Appendix D: Further Unobserved Components Model Results}

\section{SFD and Hours Worked Model}

\begin{tabular}{|c|c|c|c|}
\hline \multicolumn{4}{|c|}{ Table D1: Estimated Parameters for Hours Worked } \\
\hline \multirow[b]{2}{*}{ State } & \multicolumn{2}{|c|}{ Trend parameter, $\delta^{h}$} & \multirow{2}{*}{$\begin{array}{c}\text { Common cycle } \\
\text { response parameter, } \gamma^{h}\end{array}$} \\
\hline & 1985:Q4 - 1994:Q4 & 1995:Q1 - 2003:Q2 & \\
\hline New South Wales & 1.86 & 1.35 & 0.51 \\
\hline Victoria & 1.22 & 1.12 & 0.59 \\
\hline Queensland & 3.40 & 2.03 & 0.48 \\
\hline Western Australia & 0.84 & 0.72 & 0.54 \\
\hline South Australia & 2.69 & 1.66 & 0.40 \\
\hline Tasmania & 0.77 & 0.30 & 0.65 \\
\hline National average & 1.93 & 1.38 & 0.52 \\
\hline $\begin{array}{ll}\text { Notes: } & \text { Trend paramete } \\
& \text { cycle response } \mathrm{f} \\
& \text { the average of th }\end{array}$ & $\begin{array}{l}\text { ates can be interpretec } \\
\text { ter for NSW is norma } \\
\text { figures, weighted by t }\end{array}$ & $\begin{array}{l}\text { average annualised perc } \\
d \text { to be } 1 \text {. The "national } \\
\text { share of total hours work }\end{array}$ & $\begin{array}{l}\text { entage growth rates. The national } \\
\text { average' figures are calculated as } \\
\text { ked. }\end{array}$ \\
\hline
\end{tabular}

Table D2: Estimated $\rho$ and $\theta$ Parameters

\begin{tabular}{lc}
$\begin{array}{l}\text { National cycle coefficient, } \rho \\
\text { Nat. cycle error variance, } \sigma_{n}^{2}\end{array}$ & $\begin{array}{c}0.94 \\
6.4 \times 10^{-5}\end{array}$ \\
\hline State & $\begin{array}{c}\text { Idiosyncratic cycle response } \\
\text { coefficient, } \boldsymbol{\theta}_{\boldsymbol{i}} \text { (for hours } \text { worked) }\end{array}$ \\
\hline New South Wales & 0.61 \\
Victoria & 0.43 \\
Queensland & 0.54 \\
Western Australia & 0.25 \\
South Australia & 0.18 \\
Tasmania & 0.21 \\
\hline Notes: Sample is 1985:Q3-2003:Q2, yielding 71 observations. Idiosyncratic response \\
\hline
\end{tabular}




\begin{tabular}{lcccccc}
\hline \multicolumn{7}{c}{ Table D3: Idiosyncratic Cycle Equation Coefficients, $\mathbf{\Phi}$} \\
\hline State & NSW & VIC & QLD & WA & SA & TAS \\
\hline New South Wales & $\mathbf{0 . 8 3}$ & -0.08 & -0.10 & -0.07 & -0.07 & -0.11 \\
Victoria & 0.20 & $\mathbf{0 . 5 8}$ & -0.11 & -0.02 & -0.35 & 0.05 \\
Queensland & 0.69 & 0.41 & $\mathbf{0 . 9 5}$ & 0.65 & 0.59 & 0.45 \\
Western Australia & -0.63 & -0.53 & -0.52 & $\mathbf{0 . 4 6}$ & -0.61 & -0.14 \\
South Australia & -0.10 & -0.08 & -0.11 & -0.25 & $\mathbf{0 . 5 6}$ & 0.00 \\
Tasmania & -0.34 & 0.14 & 0.27 & -0.28 & 0.32 & $\mathbf{0 . 3 7}$ \\
\hline
\end{tabular}

\section{Table D4: Cumulative Responses To Shocks}

Hours Worked

\begin{tabular}{lccccccc}
\hline & \multicolumn{7}{c}{ Cumulative effect after eight quarters of a shock to: } \\
\cline { 2 - 8 } State & NSW & VIC & QLD & WA & SA & TAS & National \\
\hline New South Wales & $\mathbf{2 . 7}$ & -0.6 & -0.7 & -0.4 & -0.7 & -0.8 & 3.0 \\
Victoria & 0.5 & $\mathbf{0 . 8}$ & -0.4 & 0.1 & -1.2 & -0.2 & 3.5 \\
Queensland & 0.9 & 0.1 & $\mathbf{1 . 3}$ & 0.9 & 0.7 & 0.6 & 2.8 \\
Western Australia & -1.6 & -0.5 & -0.3 & $\mathbf{0 . 4}$ & -0.5 & -0.2 & 3.2 \\
South Australia & 0.5 & 0.2 & 0.2 & -0.3 & $\mathbf{0 . 9}$ & 0.1 & 2.4 \\
Tasmania & 0.5 & 0.5 & 0.5 & -0.1 & 0.7 & $\mathbf{0 . 7}$ & 3.9 \\
\hline
\end{tabular}

Notes: The cumulative response is effectively the integral between the shocked level of hours worked and the noshock counterfactual level from the shock quarter to the eighth quarter following the shock. The shocks to state idiosyncratic cycles are scaled to increase SFD in the shock state by 1 per cent in the first quarter; the shock to the common cycle is similarly scaled and is 1.95 per cent (see notes to Table 5). All shocks last one quarter, but the model dynamics imply a sustained decay path in each case. 
Figure D1: Idiosyncratic Cycle Impulse Response Functions SFD and Hours Worked Model

Shock to New South Wales

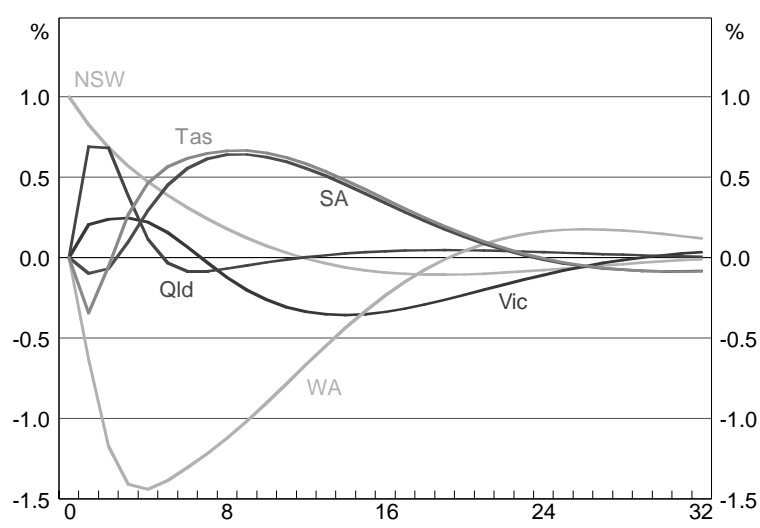

Shock to Queensland

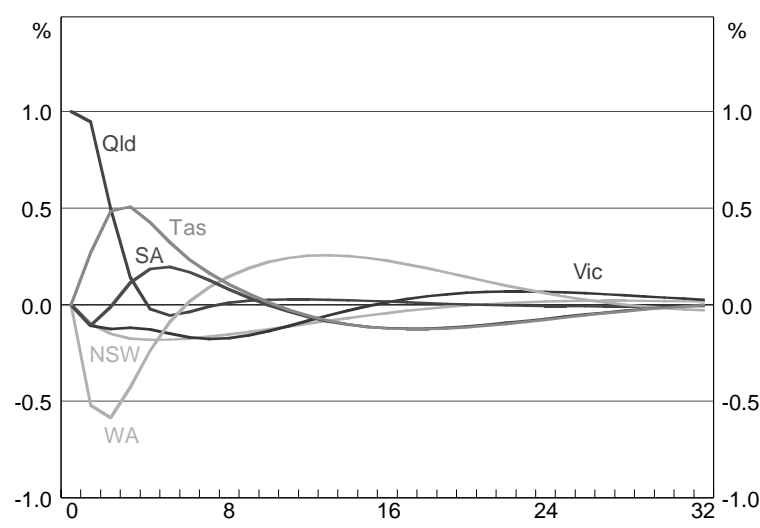

Shock to South Australia

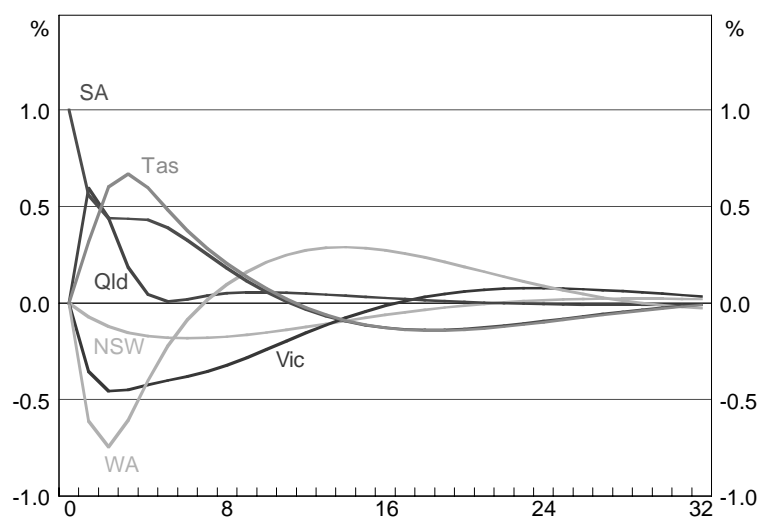

Shock to Victoria

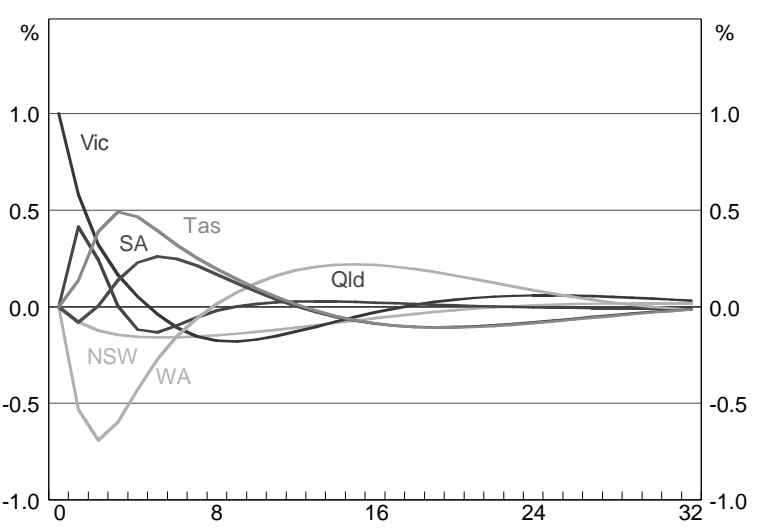

Shock to Western Australia

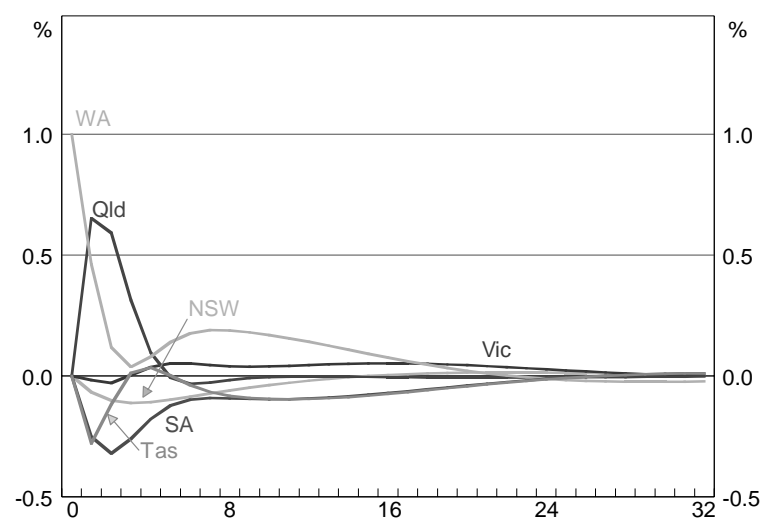

Shock to Tasmania

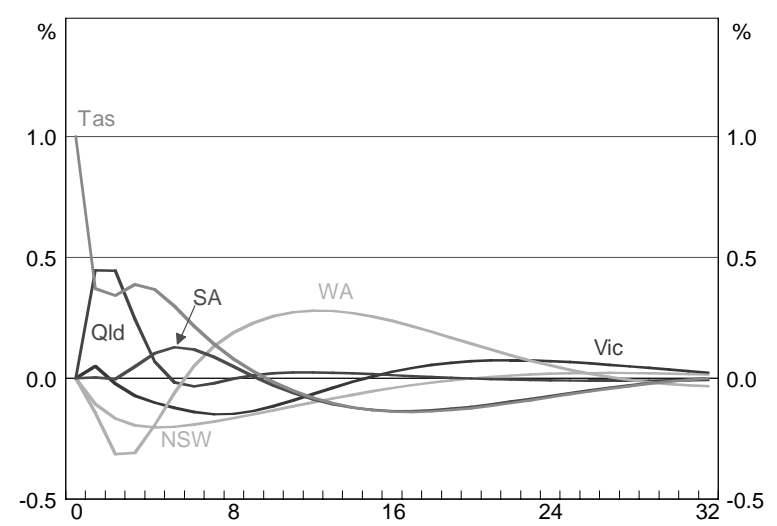




\section{Figure D2: Idiosyncratic Cycle Impulse Response Functions}

SFD and Hours Worked Model

(Suppressing interstate responses of WA and Queensland)

Shock to New South Wales

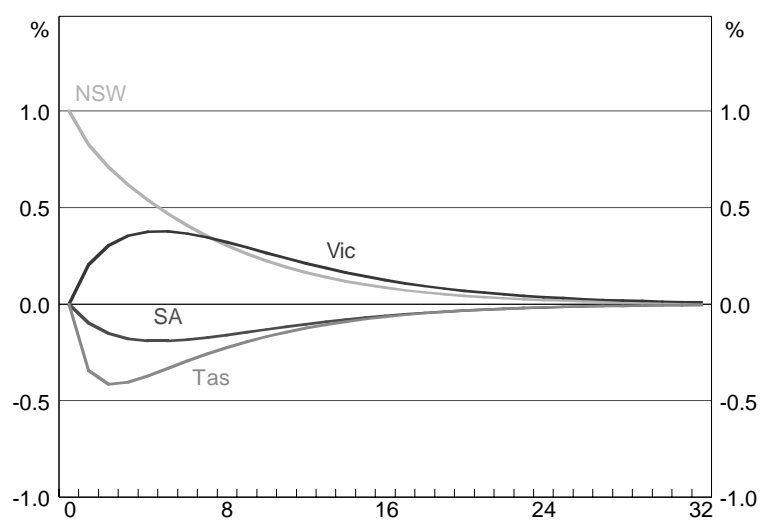

Shock to Queensland

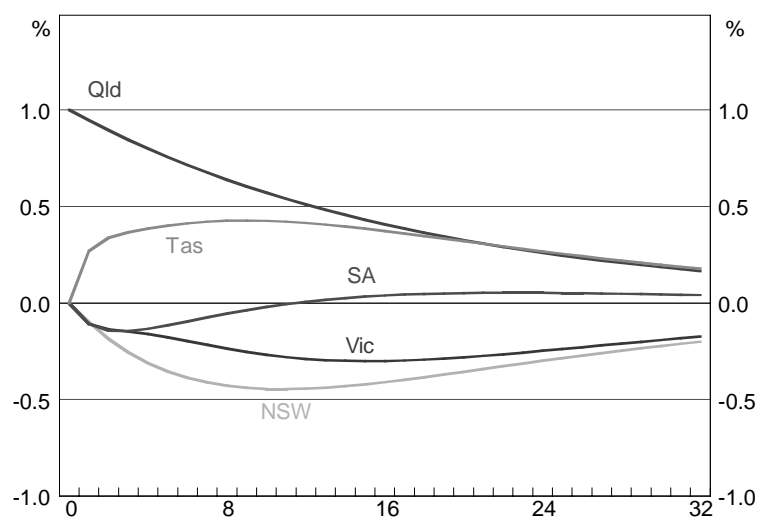

Shock to South Australia

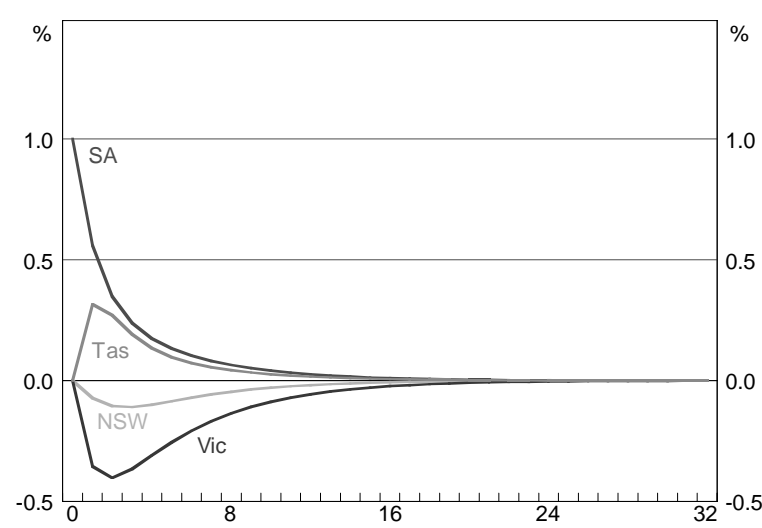

Shock to Victoria

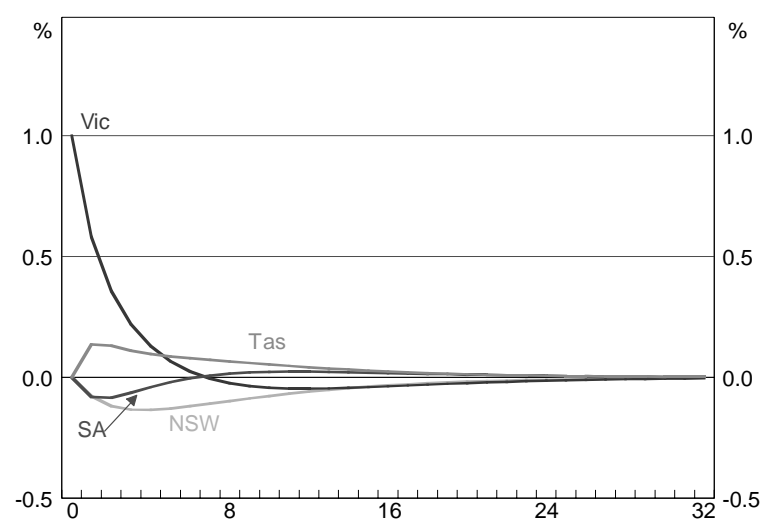

Shock to Western Australia

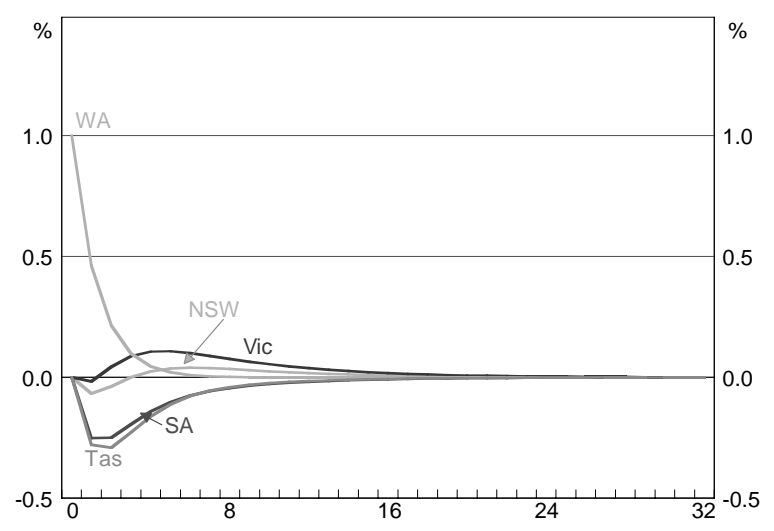

Shock to Tasmania

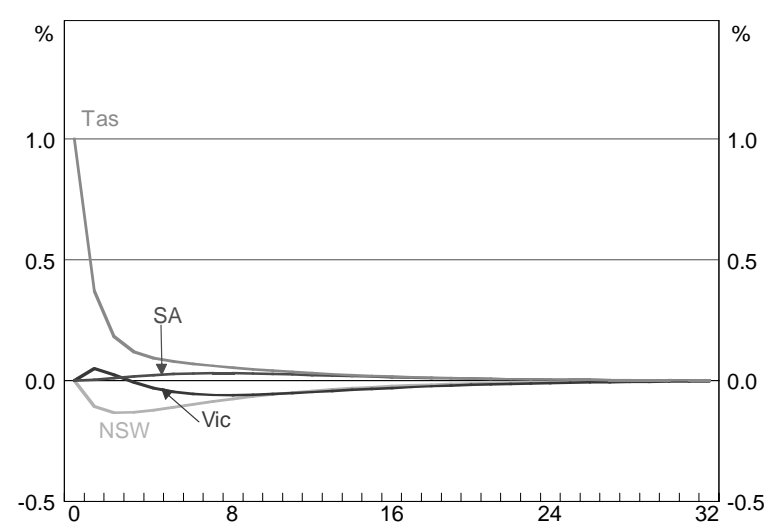


GSP and Hours Worked Model

\begin{tabular}{|c|c|c|c|}
\hline \multicolumn{4}{|c|}{ Table D5: Estimated Parameters for Gross State Product } \\
\hline \multirow[b]{2}{*}{ State } & \multicolumn{2}{|c|}{ Trend parameter, $\delta^{g}$} & \multirow{2}{*}{$\begin{array}{c}\text { Common cycle } \\
\text { response parameter, } \gamma^{g}\end{array}$} \\
\hline & 1985:Q4 - 1994:Q4 & 1995:Q1 - 2003:Q2 & \\
\hline New South Wales & 2.54 & 3.68 & 1.00 \\
\hline Victoria & 1.88 & 4.02 & 1.01 \\
\hline Queensland & 4.36 & 4.57 & 1.31 \\
\hline Western Australia & 4.67 & 3.55 & 1.76 \\
\hline South Australia & 1.45 & 2.75 & 1.03 \\
\hline Tasmania & 0.95 & 1.56 & 0.81 \\
\hline National average & 2.76 & 3.80 & 1.13 \\
\hline $\begin{array}{l}\text { Trend paramete } \\
\text { cycle response } \\
\text { the average of tl }\end{array}$ & $\begin{array}{l}\text { nates can be interprete } \\
\text { eter for NSW is norm } \\
\text { e figures, weighted by }\end{array}$ & $\begin{array}{l}\text { average annualised perc } \\
\mathrm{d} \text { to be } 1 \text {. The "national } \\
\text { r share of total GSP. }\end{array}$ & $\begin{array}{l}\text { Entage growth rates. The national } \\
\text { average' figures are calculated as }\end{array}$ \\
\hline
\end{tabular}

Table D6: Estimated $\rho$ and $\theta$ Parameters

$\begin{array}{lc}\text { Common cycle coefficient, } \rho & 0.93 \\ \text { Common cycle error variance, } \sigma_{n}^{2} & 6.4 \times 10^{-5}\end{array}$

State

Idiosyncratic cycle response coefficient, $\theta_{i}$ (for hours worked)

\begin{tabular}{ll}
\hline New South Wales & 0.41 \\
Victoria & 0.41 \\
Queensland & 0.22 \\
Western Australia & 0.07 \\
South Australia & 0.18 \\
Tasmania & 0.48 \\
\hline Notes: Sample is 1985:Q3-2003:Q2, yielding 71 observations. Idiosyncratic response \\
\hline
\end{tabular}


Table D7: Idiosyncratic Cycle Equation Coefficients, $\Phi$

\begin{tabular}{lrrrrrr}
\hline State & NSW & VIC & QLD & WA & SA & TAS \\
\hline New South Wales & $\mathbf{0 . 6 7}$ & -0.07 & -0.22 & -0.06 & -0.14 & -0.07 \\
Victoria & -0.04 & $\mathbf{0 . 4 9}$ & -0.13 & -0.12 & -0.27 & -0.23 \\
Queensland & -0.17 & -0.29 & $\mathbf{0 . 2 4}$ & 0.15 & -0.20 & -0.17 \\
Western Australia & 1.03 & 1.29 & 1.35 & $\mathbf{1 . 1 1}$ & 0.94 & 1.15 \\
South Australia & -0.41 & -0.32 & -0.34 & -0.24 & $\mathbf{0 . 4 9}$ & -0.28 \\
Tasmania & -0.50 & -0.42 & -0.32 & -0.22 & -0.16 & $\mathbf{0 . 4 5}$ \\
\hline
\end{tabular}




\section{Appendix E: Data Sources}

\section{State Final Demand}

Data are seasonally adjusted, in chain volume terms, 2001/02 prices, from Australian Bureau of Statistics (ABS), Australian National Accounts: National Income, Expenditure and Product, 5206.0 (various tables), December 2003.

\section{Hours Worked}

Data are total hours worked per state, in the reference week for the relevant quarter, obtained from ABS, Labour Force Statistics, Tables LHQI-103, -203, 303, -403, -503 and -603, April 2004.

\section{Gross State Product}

Annual

Data in chain volume terms, 2001/02 prices, from ABS, Australian State Accounts, 5220.0 (Table 1), June 2003.

Quarterly

Data are seasonally adjusted, in constant price terms, 1989/90 prices. Obtained from ABS, Australian National Accounts: State Accounts, 5242.0, using the latest data for each quarter as reported in the December 1992 to June 1997 publications. Adjustments to 2001/02 prices were made using state final demand deflators from 5206.0 (National Accounts). 


\section{References}

Altonji J and J Ham (1990), 'Variation in employment growth in Canada: The role of external, national, regional and industrial factors', Journal of Labour Economics, 8(1), pp S198-S236.

Artis M, Z Kontelemis and D Osborn (1997), 'Classical business cycles for G-7 and European countries', Journal of Business, 70(2), pp 249-279.

Barrios S and J de Lucio (2003), 'Economic integration and regional business cycles: Evidence from the Iberian regions', Oxford Bulletin of Economics and Statistics, 64(4), pp 497-515.

Barrios S, M Brülhart, RJR Elliott and M Sensier (2003), 'A tale of two cities: Co-fluctuations between U.K. regions and the Euro zone', Manchester School, 71(3), pp 265-292.

Baxter M and R King (1999), 'Measuring business cycles: Approximate band pass filters for economic time series', Review of Economics and Statistics, 81(4), pp 575-593.

Beveridge S and CR Nelson (1981), 'A new approach to decomposition of economic time series into permanent and transitory components with particular attention to the measurement of the "business cycle", Journal of Monetary Economics, 7(2), pp 151-174.

Bry G and C Boschan (1971), Cyclical Analysis of Time Series: Selected procedures and computer programs, NBER, New York.

Burns A and W Mitchell (1946), Measuring Business Cycles, NBER, New York.

Canova F (1998), 'Detrending and business cycle facts', Journal of Monetary Economics, 41(3), pp 475-512. 
Carlino G and K Sill (1997), 'Regional economies: Separating trends from cycles', Federal Reserve Bank of Philadelphia Business Review, May/June 1997, pp 1-13.

Carlino G and R DeFina (1995), 'Regional income dynamics', Journal of Urban Economics, 37, pp 88-106.

Chow GC and A Lin (1971), 'Best linear unbiased interpolation, distribution, and extrapolation of time series by related series', Review of Economics and Statistics, 53(4), pp 372-375.

Clark T and K Shin (2000), 'The sources of fluctuations within and across countries', in G Hess and E van Wincoop (eds), Intranational Macroeconomics, Cambridge University Press.

Debelle G and J Vickery (1999), 'Labour market adjustment: Evidence on interstate labour mobility', Australian Economic Review, 32(3), pp 249-263.

Dixon R and D Shepherd (2001), 'Trends and cycles in Australian state and territory unemployment rates', Economic Record, 77(238), pp 252-269.

Forni M, M Hallin, M Lippi and L Reichlin (2001), 'The generalized dynamicfactor model: Identification and estimation', Review of Economics and Statistics, 82(4), pp 540-554.

Hall V, K Kim and R Buckle (1998), 'Pacific rim business cycle analysis: Synchronisation and volatility', New Zealand Economic Papers, 32(2), pp 129159.

Hamilton J D (1994), Time Series Analysis, Princeton University Press.

Harding D and A Pagan (2002), 'Dissecting the cycle: A methodological investigation', Journal of Monetary Economics, 49(2), pp 365-381. 
Kouparitsas M (2002), 'Understanding U.S. regional cyclical comovement: How important are spillovers and common shocks?', Federal Reserve Bank of Chicago Economic Perspectives, 26(4), pp 30-41.

Krugman P (1991), Geography and Trade, MIT Press.

Labhard V (2003), 'What caused the 2000/01 slowdown? Results from a VAR analysis of G7 GDP components', Bank of England Working Paper No. 190.

McDermott J and A Scott (2000), 'Concordance in business cycles', IMF Working Paper No. 00/37.

Miller I and M Miller (1999), John E. Freund's Mathematical Statistics, Sixth Edition, Prentice Hall, New Jersey,.

Norrbin S and D Schlagenhauf (1996), 'The role of international factors in the business cycle: A multi-country study', Journal of International Economics, 40(1-2), pp 85-104.

Owyang M, J Piger and H Wall (2003), 'Business cycle phases in U.S. states', Federal Reserve Bank of St. Louis Working Paper No. 2003-011.

Pedersen T (2001), 'The Hodrick-Prescott filter, the Slutzsky effect, and the distortionary effect of filters', Journal of Economic Dynamics and Control, 25(8), pp 1081-1101.

Rissman E (1999), 'Regional employment growth and the business cycle', Economic Perspectives, 23(4), pp 21-39.

Stock J and M Watson (2003), 'Understanding changes in international business cycle dynamics', NBER Working Paper No. 9859.

Watson M (1986), 'Univariate detrending methods with stochastic trends', Journal of Monetary Economics, 18(1), pp 49-75. 
Watson $M$ and RF Engle (1983), 'Alternative algorithms for the estimation of dynamic factor, MIMIC and varying coefficient regression models', Journal of Econometrics, 23(3), pp 385-400.

Weber E (2003), 'Monetary policy in a heterogenous monetary union: The Australian experience', Mimeo, University of Western Australia, December.

Wecker W (1979), 'Predicting the turning points of a time series', Journal of Business, 52(1), pp 35-50. 